\title{
A Radical Approach to Anionic Chemistry: Synthesis of Ketones, Alcohols, and Amines
}

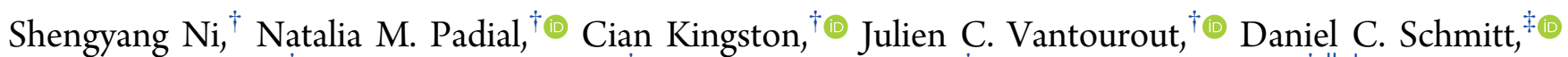
Jacob T. Edwards, ${ }^{\dagger}$ Monika M. Kruszyk, ${ }^{\dagger}$ Rohan R. Merchant, ${ }^{\dagger}$ Pavel K. Mykhailiuk, ${ }^{\dagger, \|, \perp}$ Brittany B. Sanchez, ${ }^{\nabla}$ Shouliang Yang, Matthew A. Perry, Gary M. Gallego, ${ }_{\triangleright}^{\ddagger}$ James J. Mousseau, ${ }^{\ddagger}$ Michael R. Collins, ${ }^{\S}$ Robert J. Cherney, ${ }^{\otimes}$ Pavlo S. Lebed, ${ }^{\perp, \#}$ Jason S. Chen, ${ }^{\nabla}$ Tian Qin, ${ }^{\dagger}$ and Phil S. Baran* ${ }^{* \dagger}$

${ }^{\dagger}$ Department of Chemistry, Scripps Research, 10550 North Torrey Pines Road, La Jolla, California 92037, United States

${ }^{\ddagger}$ Pfizer Medicinal Sciences, Eastern Point Road, Groton, Connecticut 06340, United States

${ }^{\S}$ Department of Chemistry, La Jolla Laboratories, Pfizer 10770 Science Center Drive, San Diego, California 92121, United States

${ }^{\perp}$ Enamine Ltd., Chervonotkatska 78, 02094 Kyiv, Ukraine

"Chemistry Department, Taras Shevchenko National University of Kyiv, Volodymyrska 64, 01601 Kyiv, Ukraine

${ }^{\#}$ ChemBioCenter, Taras Shevchenko National University of Kyiv, Volodymyrska 64, 01601 Kyiv, Ukraine

${ }^{\nabla}$ Automated Synthesis Facility, Scripps Research, 10550 North Torrey Pines Road, La Jolla, California 92037, United States

${ }^{\otimes}$ Research \& Development, Bristol-Myers Squibb Company, Rt. 206 \& Province Line Road, Princeton, New Jersey 08543, United States

Supporting Information

ABSTRACT: Historically accessed through two-electron, anionic chemistry, ketones, alcohols, and amines are of foundational importance to the practice of organic synthesis. After placing this work in proper historical context, this Article reports the development, full scope, and a mechanistic picture for a strikingly different way of forging such functional groups. Thus, carboxylic acids, once converted to redox-active esters (RAEs), can be utilized as formally nucleophilic coupling

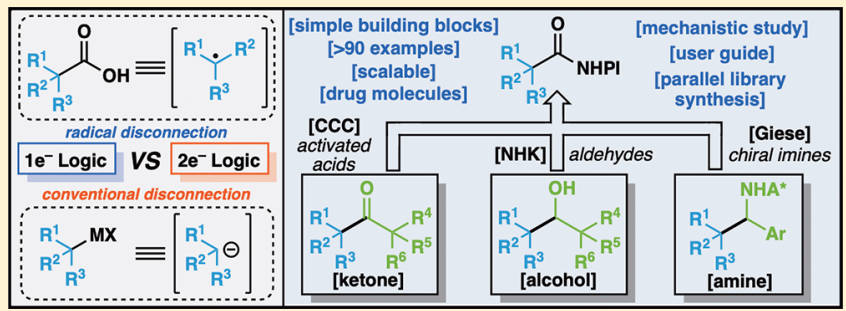
partners with other carboxylic derivatives (to produce ketones), imines (to produce benzylic amines), or aldehydes (to produce alcohols). The reactions are uniformly mild, operationally simple, and, in the case of ketone synthesis, broad in scope (including several applications to the simplification of synthetic problems and to parallel synthesis). Finally, an extensive mechanistic study of the ketone synthesis is performed to trace the elementary steps of the catalytic cycle and provide the end-user with a clear and understandable rationale for the selectivity, role of additives, and underlying driving forces involved.

\section{INTRODUCTION}

Roughly 120 years ago, Grignard invented his eponymous reaction that converts alkyl halides into nucleophilic organomagnesium reagents that engage electrophilic $\mathrm{C}=\mathrm{O}$ bonds. ${ }^{1}$ This reaction forms one of the foundational reactions of organic synthesis and although the precise mechanism of carbonyl addition is not fully understood, it is generally regarded (and taught to undergraduates) as a two-electron (anionic) process. ${ }^{2}$ Grignard reagents and related species are routinely used to generate some of the most useful functional groups such as ketones (via addition to activated ester or amide derivatives), alcohols (via addition to aldehydes), and amines (via addition to imines), as depicted in Figure $1 .^{3}$ Notwithstanding its indisputable utility and broad scope, it bears with it a restricted window of chemoselectivity-certain functional groups are simply not compatible with the highly basic and nucleophilic properties of the reagents. Additionally, alkyl halides are often inconvenient to prepare and scarcely available compared to other feedstock functional groups such as olefins and carboxylic acids. ${ }^{4}$ Thus, the search for Grignardlike reactivity that is milder and more tolerant of air and moisture continues to the present day. ${ }^{5}$ Indeed, groundbreaking findings from Lipshutz, Buchwald, Krische, and Miura have opened up a realm of mild nucleophilic additions beginning with olefin precursors. ${ }^{6} \mathrm{We}$ and others have also explored how Mukaiyama-type reactivity can be harnessed on olefins to add to carbonyl groups. ${ }^{7}$

In the quest for practicality, alkyl carboxylic acids are perhaps the most ubiquitous functional group from the

Received: February 27, 2019

Published: April 3, 2019 


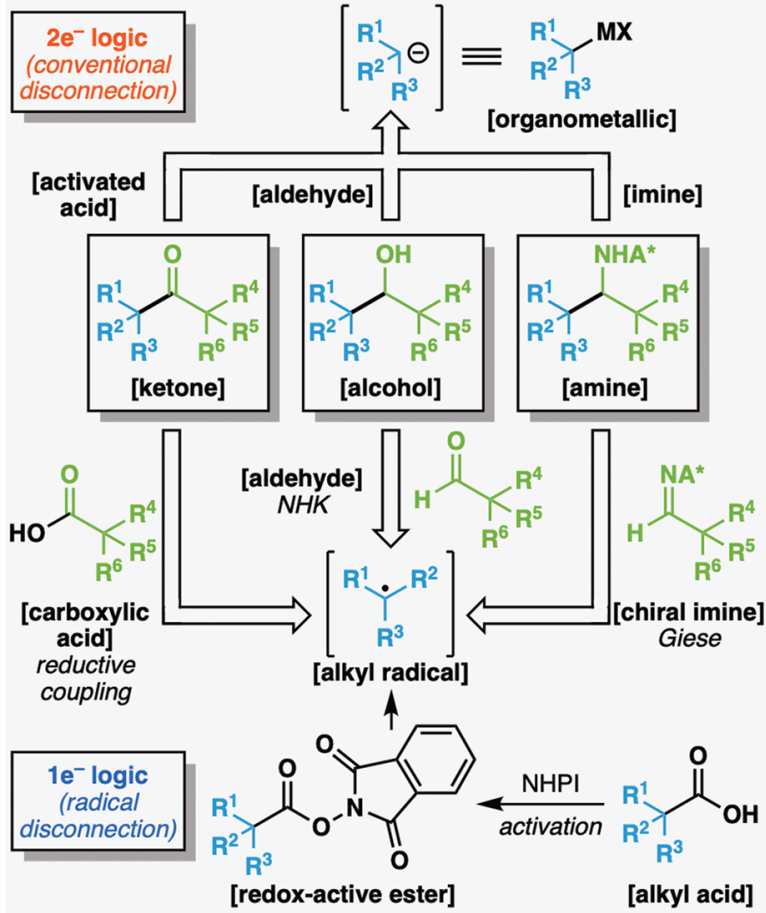

Figure 1. Polar-bond disconnections via conventional $2 \mathrm{e}^{-}$logic vs newly explored radical processes for ketone, alcohol, and amine synthesis. NHPI $=N$-hydroxyphthalimide. standpoint of commercial availability. ${ }^{8}$ They are uniquely modular building blocks in that they can be easily diversified at the alpha-position using anionic chemistry and then disassembled to lose $\mathrm{CO}_{2}$ and afford a carbon-centered radical. Radicals derived in this way have a storied history dating back to Kolbe and Barton's legendary findings. ${ }^{9}$ More recently, we and others have explored how such radicals could be generated in the same way that alkyl halide-derived radicals have been for decades using transition metals. ${ }^{10}$ Thus far, most recent studies in this area have been focused on the canonical chemistry of radicals such as their use in cross-coupling and trapping with radicalophiles. $^{11}$

The focus of this work was to see if carboxylate-derived radicals could be engaged in reaction manifolds that have historically been within the purview of anionic (Grignard) chemistry. This Article describes the invention, full scope and limitations, and detailed mechanism of methods for harnessing radicals derived from redox-active esters (RAEs) for reactions with electrophilic $\mathrm{C}=\mathrm{X}$ bonds to generate ketones, alcohols, and amines.

\section{BACKGROUND AND HISTORICAL CONTEXT}

The generation of radicals and subsequent interception with transition metals for the specific purpose of adding to $\mathrm{C}=\mathrm{X}$ bonds is not new (Figure 2). In fact, this area has a long history dating back to the late 1970s. Figure 2 outlines the key precedents in this area that have laid the strategic and mechanistic basis for the current studies. Early work in this area focused on the use of electrochemical techniques to generate alkyl-M species $(\mathrm{M}=\mathrm{Cd}$ and $\mathrm{Mg})$ that could be

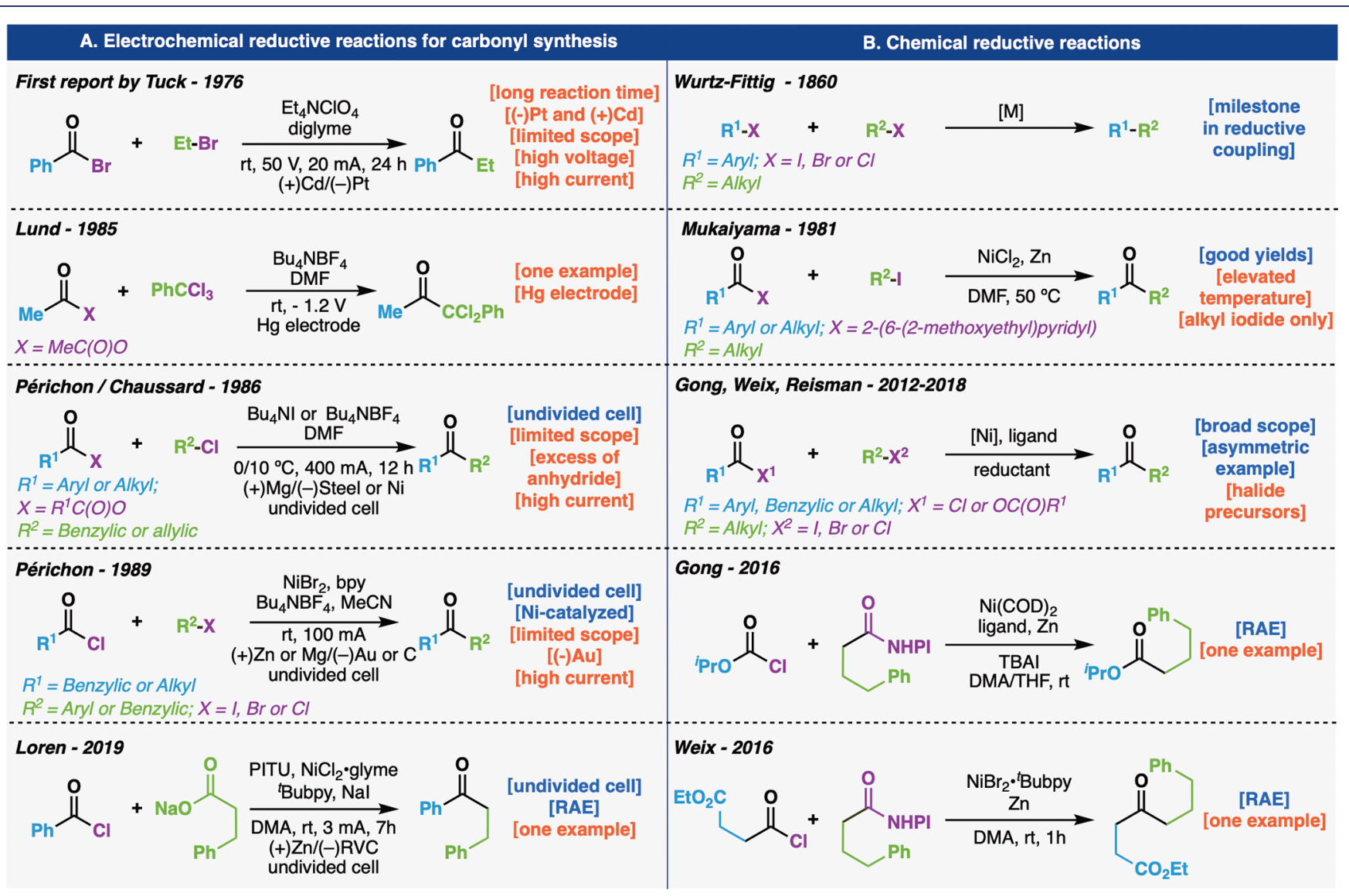

Figure 2. Radical methods for accessing carbonyl compounds: historical perspective. NHPI = N-hydroxyphthalimide. 
directly added to acyl halides in situ. ${ }^{12}$ Lund and co-workers subsequently demonstrated that anhydrides were also suitable electrophiles in this transformation. ${ }^{13}$ One of the key breakthroughs in this area can be traced to a report by Périchon who laid some of the groundwork for the crosselectrophile couplings of the modern era. ${ }^{14}$ In that work, a sacrificial anode such as zinc was utilized in an undivided cell along with catalytic nickel in the presence of a diamine ligand (bpy) to couple simple alkyl and acyl halides to form ketones. In parallel to these electrochemical studies, Mukaiyama and coworkers demonstrated a similar transformation by embedding the ligand for $\mathrm{Ni}$ onto the ester (2-pyridyl ester derivatives) rather than using an acyl halide. ${ }^{15}$ Moving to the modern era, the field of reductive/cross electrophile couplings, specifically those between alkyl halides and acyl halides/anhydrides, has flourished with impactful contributions from the Martin, Gong, Weix, and Reisman groups among many others. ${ }^{16}$ Finally, the Gong, Weix, and Loren teams have reported single examples of the use of RAEs in place of alkyl halides for ester (Gong) or ketone (Weix and Loren) synthesis. ${ }^{17}$ This backdrop of precedent places our studies in a proper context.

\section{KETONE SYNTHESIS VIA CROSS-CARBOXY COUPLING: DEVELOPMENT AND SCOPE}

Retrosynthetic considerations for the synthesis of complex ketones inspired our explorations in this area. For example, as illustrated in Figure 3A, ketone fragment $\mathbf{1}$ was enlisted as a key intermediate in a total synthesis of anamarine 2. Prior routes to this ketone, which conveniently maps onto readily available tartaric acid, relied on $2 \mathrm{e}^{-}$logic and thus could not easily take advantage of this inexpensive building block because anionic chemistry of the type shown in Figure 3A is not workable. $^{18}$ Therefore, an olefin-based route was pursued requiring two asymmetric dihydroxylations with Os along with extraneous redox fluctuations and PGs (8 steps overall). In contrast, $1 \mathrm{e}^{-}$logic pointed to a simple (3-step) means of utilizing feedstock chiral pool materials: tartaric and lactic acid. The development of the necessary chemistry to achieve this simplification was accomplished using model substrates 3 and 4 as outlined in Figure 3B. In its fully optimized manifestation, a 73\% isolated yield of ketone 5 was obtained from RAE 4 and acid 3 using a carefully engineered set of reagents in concert with a Ni catalyst: (1) benzoic anhydride as activating agent for the carboxylic acid, (2) $\mathrm{Zn}$ powder as reducing agent, and (3) magnesium- and lithium-based Lewis acids $\left(\mathrm{MgCl}_{2}\right.$ and $\mathrm{LiBr})$. The experimental simplicity is worth pointing out: all components are simply added to a flask followed by addition of solvent, and after $3 \mathrm{~h}$ of stirring at room temperature the reaction is stopped. Deviations from the conditions prescribed above are certainly tolerated.

For instance, the following set of modifications resulted in only $5-15 \%$ decrease in yield: running the reaction under air (entry 2), generating either the RAE (entry 3) or catalyst (entry 4) in situ, reducing the equivalents of acid and anhydride (entry 5), or lowering the catalyst loading (entry 6). Key parameters for the success of this reaction include the specific identity of the RAE (entry 7), Ni-bound ligand (entry 8 ), anhydride (entries 9 and 10), reductant (entry 11), and Lewis acids employed (entries 12-14). Unsurprisingly, inclusion of the anhydride was found to be required for product formation (entry 15). In addition, the use of an acyl chloride in place of the in situ combination of carboxylic acid and anhydride led to even higher conversion (entry 16). For

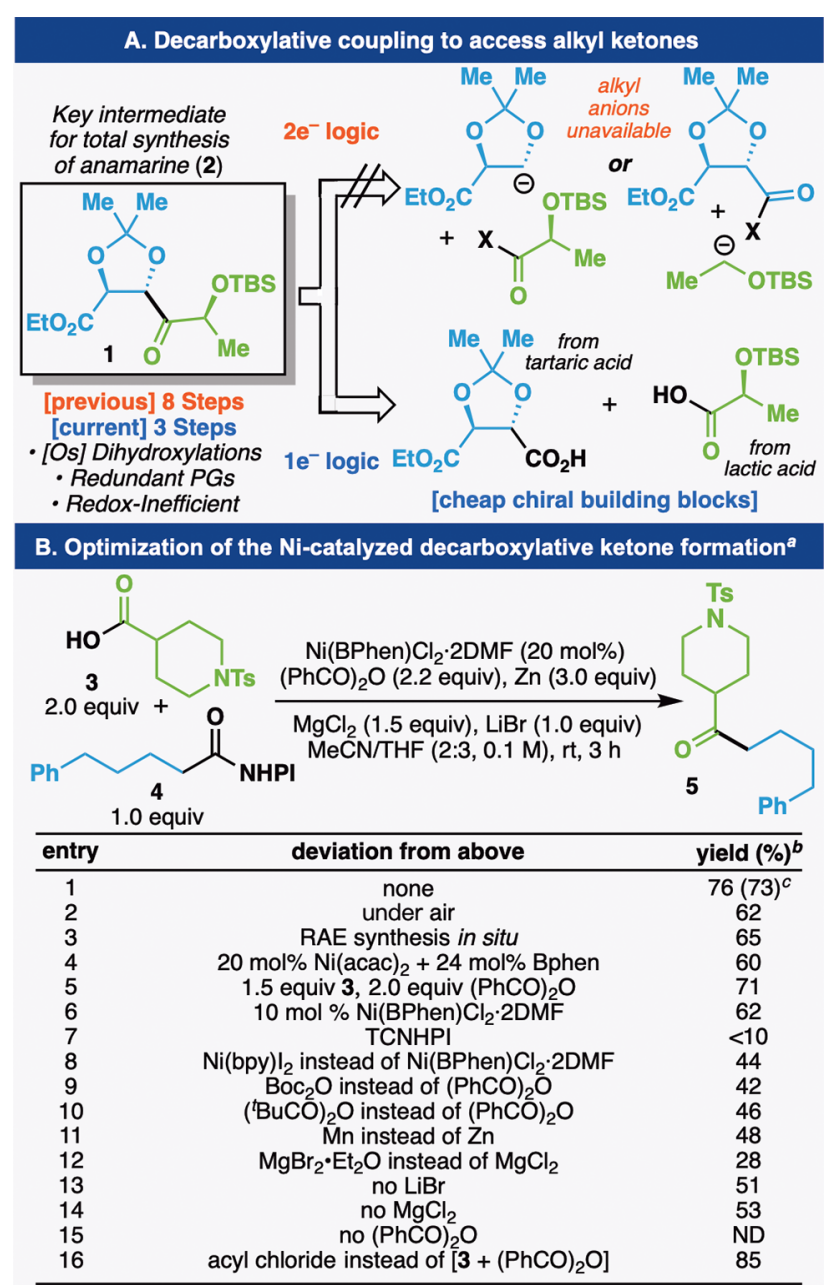

Figure 3. (A) Inspiration for a mild ketone and chemoselective ketone synthesis and (B) development and optimization of CCC. ${ }^{a}$ 0.1 mmol. ${ }^{b}$ Yield determined by LC-MS with 1,3,5-trimethoxybenzene as an internal standard. ${ }^{c}$ Isolated yield. See Supporting Information for details. NHPI $=N$-hydroxyphthalimide, TCNHPI $=$ $\mathrm{N}$-hydroxytetrachlorophthalimide, bpy $=2,2^{\prime}$-bipyridine, $\mathrm{BPhen}=$ bathophenanthroline, ND = not detected.

the sake of experimental simplicity and to enable parallel library synthesis (vide infra), the in situ protocol was adopted as the standard protocol. An extensive list of parameters screened can be found in the Supporting Information (SI), and the role of each component will be discussed in the Mechanistic Inquiry section (vide infra).

With a set of optimized conditions in hand the scope and versatility of ketone synthesis was systematically explored employing a range of different carboxylic acids (Table 1). This "cross-carboxy coupling" (CCC) tolerates a range of $1^{\circ}, 2^{\circ}, 3^{\circ}$, and aromatic carboxylic acids to deliver unsymmetrical ketones in an operationally simple, chemoselective, and scalable way. $1^{\circ}$ RAEs were coupled to $1^{\circ}(6,7,9,11$, and 13$), 2^{\circ}(5,8,10$, $12,14-17,19,20,22$, and 23$)$, and bridged $3^{\circ}(21)$ carboxylic acids in good yields. A large variety of functional groups including esters (6), ketones $(7-9,11,12$, and 19), $N$ Boc $(9,14,16$, and 23$)$ or $N$-tosyl $(5,8,10,12,14-17$, and 20) protected amines, amides ( 22 and 23 ), ethers ( 7 and 17 ), and halogens $(10,13,15,20,22$, and 23$)$ were tolerated under the reaction conditions. In addition, successful functionalization of fenbufen and indomethacin was achieved to afford 
Table 1. Scope of the CCC Ketone Synthesis
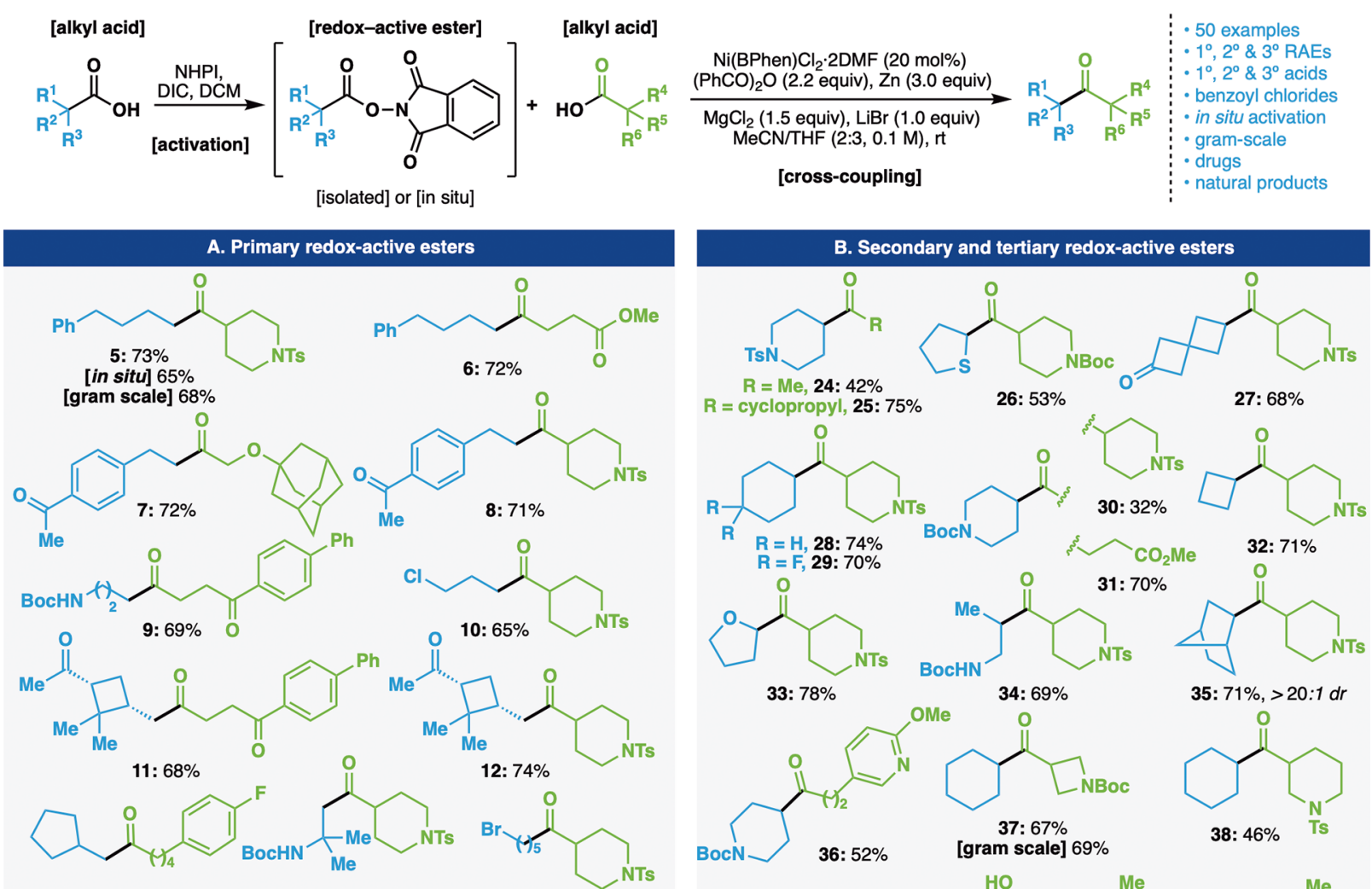

33: $78 \%$

5: $71 \%,>20: 1 d r$<smiles>COc1ccc(CC(=O)C2CCN(C(=O)OC(C)(C)C)CC2)cn1</smiles>

$35.71 \%,>20: 1$ dr

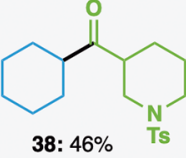

13: $70 \%$

14: $66 \%$

15: $71 \%$
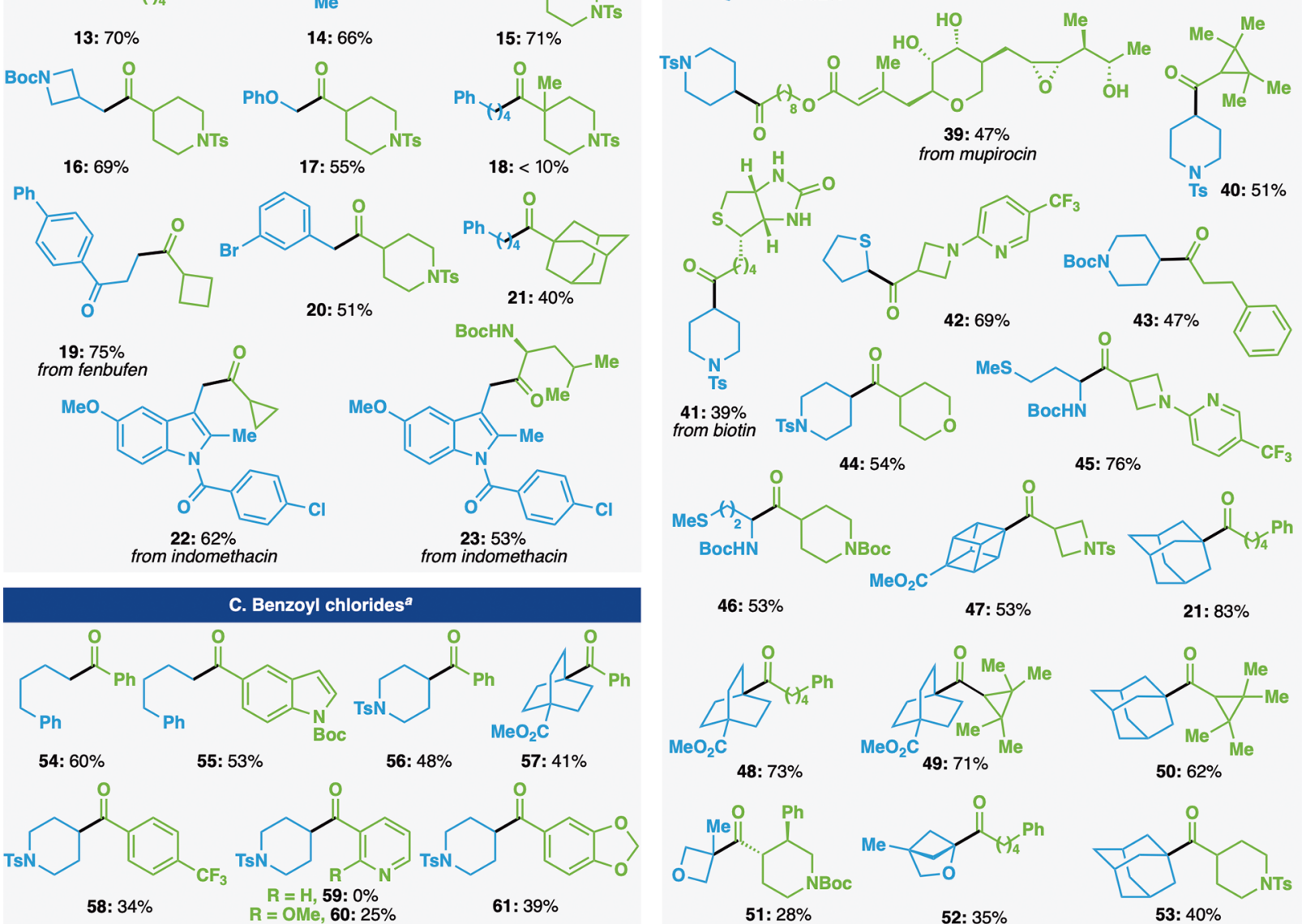

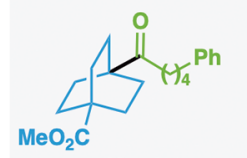

48: $73 \%$

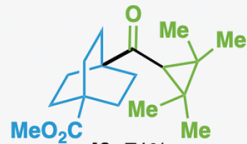

$\mathrm{MeO}_{2} \mathrm{C}_{49:}$ 71\%
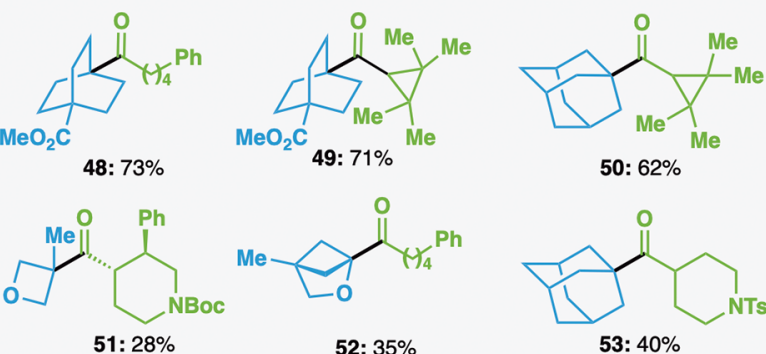

52: $35 \%$

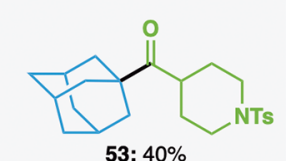

${ }^{a}$ Using benzoyl chlorides (2.0 equiv) instead of $\left[\right.$ acid $\left.+(\mathrm{PhCO})_{2} \mathrm{O}\right]$. DIC $=\mathrm{N}, \mathrm{N}^{\prime}$-diisopropylcarbodiimide. Yields of isolated products are indicated in each case. Standard reaction conditions: RAE (1.0 equiv), carboxylic acid (2.0 equiv), Ni(BPhen) $\mathrm{Cl}_{2} \cdot 2 \mathrm{DMF}(20 \mathrm{~mol} \%), \mathrm{Zn}(3.0$ equiv), $(\mathrm{PhCO})_{2} \mathrm{O}$ (2.2 equiv), $\mathrm{MgCl}_{2}$ (1.5 equiv), $\mathrm{LiBr}$ (1.0 equiv), $\mathrm{MeCN} / \mathrm{THF}(2: 3,0.1 \mathrm{M}), \mathrm{rt}, 3 \mathrm{~h}$. 
compounds 19, 22, and 23 in $75 \%, 62 \%$ and $53 \%$ yield, respectively. $2^{\circ}$ and $3^{\circ}$ RAEs were also coupled to a broad range of $1^{\circ}\left(21,24,31,36,39,41,43,48\right.$, and 52) and $2^{\circ}$ (25-30, 32-35, 37, 38, 40, 42, 44-47, 49-51, and 53) carboxylic acids with similarly exceptional levels of chemoselectivity, including a diol, an epoxide, and a Michael acceptor found on mupirocin (39). Although bridged $3^{\circ}$ carboxylic acids and RAEs were well tolerated, lower yields were observed in the case of exceedingly sterically encumbered moieties (18). It is worth noting that the diversification of biotin, ${ }^{19}$ a highly polar and oft installed structure in chemical biology was also successful (41). Strikingly, almost $90 \%$ of the compounds illustrated in Table 1 have never been prepared before, thereby illustrating the capability CCC to access new chemical space. For example, the successful coupling of bridged compounds such as cubane 47 and 2-oxabicyclo[2.1.1] hexane 52 provides a versatile entry into these useful phenyl ring bioisosteres. ${ }^{20}$ Pleasingly, the developed conditions were easily translated to gram scale experiments affording compounds 5 and 37 in $68 \%$ and $69 \%$, respectively.

When attempting CCC on aryl carboxylic acids, minimal product formation was observed (see SI for optimization details). In this instance, modification of the coupling partner to acyl chlorides, as pioneered by Weix and Loren, ${ }^{17}$ afforded the desired products in suitable yields (54-58, 60, and 61). Tolerance of protected indole, amine, and ester functionality was observed $(\mathbf{5 5}, \mathbf{5 6}$, and $\mathbf{5 7}$, for example), although an orthomethoxy group was required in the case of a pyridine-based substrate (59 and 60).

The range of conceivable coupling partners in CCC is vast and thus from a practitioner's perspective it may not be intuitive as to which acids serve the role of electrophile/ nucleophile. For instance, substrate 21 can be prepared in either fashion (see SI for additional examples). Thus, Table 2

Table 2. An Empirically Derived User Guide for CCC

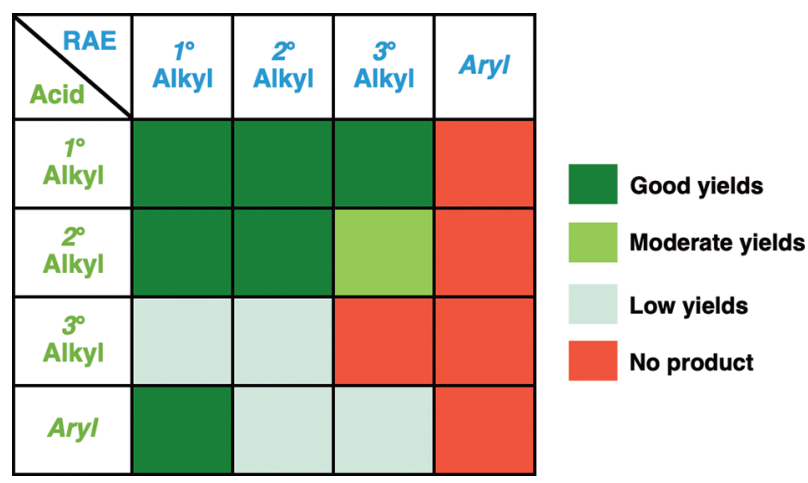

presents a convenient user guide for CCC based on the 16 possible combinations of cross coupling based on empirical findings. For example, in the case of $1^{\circ}$ and $2^{\circ}$ couplings, the starting acids can be used in either form (free acid or RAE) whereas benzoyl chlorides are best employed as the free carboxylic acid component in all couplings. Returning to the original inspiration for the development of this method, Figure 4 outlines a series of applications that serve to simplify synthesis. As depicted in Figure 4A, building block 1, previously prepared through an 8-step sequence relying on olefin functionalization, ${ }^{18}$ could now be accessed in 3 steps commencing from tartrate-derived acid 62. Subjecting this acid to CCC using commercial lactate-derived acid 63 delivered 1 in $52 \%$ yield as a single stereoisomer. It should be noted that in the CCC stereoselectivity of the RAE fragment is usually eroded via the planar radical intermediate, however in this case selectivity is guided by the conformation of the starting material. In a similar vein, muscone 64 , a widely employed fragrance additive, has previously been prepared through $\mathrm{RCM} /$ hydrogenation of diene $65^{21}$ The preparation of this simple ketone commences from a relatively expensive alcohol 66 (by fragrance industry standards) and employs three reactions to generate one new $\mathrm{C}-\mathrm{C}$ bond with the correct ketone oxidation state. In contrast, 10-undecenoic acid 67 is roughly an order of magnitude less expensive and can be smoothly converted to the same building block 65 in $68 \%$ yield upon CCC with citronellic acid 68. This 1-step process avoids halide waste, water-sensitive Grignard reagents, and excess chromium waste (employed solely for the purpose of alcohol oxidation). The experimental simplicity of this method makes it perfectly suited to a parallel library synthesis workflow. Thus, a curated set of diverse building blocks from the Pfizer collection were chosen and subjected to ketone synthesis using 1-cyclopentane carboxylic acid-derived NHPI ester 69. All reagents, with the exception of zinc, were added as stock solutions to facilitate parallel execution in plate format. HPLC analysis indicated that 19 of the 20 substrates (70-89) successfully underwent CCC, while 17 provided sufficient material after isolation $(>1.0 \mathrm{mg}$ ) for submission to standard bioactivity assays. Compound $\mathbf{8 1}$ was not isolated presumably due to the basic work up procedure used to facilitate isolation. The resulting ketones possess drug-like properties, conforming with Lipinski's "rule of five" (mean molecular weight 371, mean ClogP 4.4, mean hydrogen bond acceptor count 2.5) and include a range of common heterocycles. ${ }^{22}$ This protocol is particularly well-suited for fragment-based drug discovery (FBDD), ${ }^{23}$ or as a diversity incorporating event in multistep parallel library construction (e.g., with subsequent reductive amination).

\section{ASYMMETRIC SYNTHESIS OF BENZYLIC AMINES}

Compelled by ongoing medicinal chemistry projects at Pfizer, attention then turned to how the putatively nucleophilic species generated from RAEs under $\mathrm{Ni}$ catalysis could be engaged by other electrophilic species such as imines. ${ }^{24}$ Prior studies from our laboratories (Figure 5A) focused on the synthesis of enantiopure amino acids using the glyoxyl-derived chiral sulfinyl imine reagent $90{ }^{11 \mathrm{n}}$ That chemistry exhibits remarkable substrate scope and utilizes a TCNHPI-based RAE in concert with an inexpensive reducing agent $(\mathrm{Zn})$ and catalyst $\left[\mathrm{Ni}(\mathrm{OAc})_{2} \cdot 4 \mathrm{H}_{2} \mathrm{O}\right]$. Translation of those exact conditions using the less electrophilic aryl sulfinyl imines in order to generate enantiopure benzylic amines furnished only trace product (Figure $5 \mathrm{~B}$, entry 1 ). Thus, a thorough reexamination of conditions was pursued culminating in the identification of a mild and robust set of conditions (entry 3 ). Three key modifications relative to prior studies were an increased concentration ( 0.2 vs $1.0 \mathrm{M}$, entry 10$)$, use of NHPI instead of TCNHPI as the RAE (entry 6) and a more reactive reducing agent (standard zinc powder vs zinc nanopowder, entry 8). This unique form of zinc, available from SigmaAldrich, was also found to be critical in radical couplings in DNA-encoded library synthesis. ${ }^{11 \mathrm{k}}$ Similar to ketone synthesis via CCC, the reaction tolerates air/moisture (entry 4) and the RAE can be made in situ to enable parallel synthesis endeavors (entry 5). Attempts to utilize the corresponding Ellman imine 


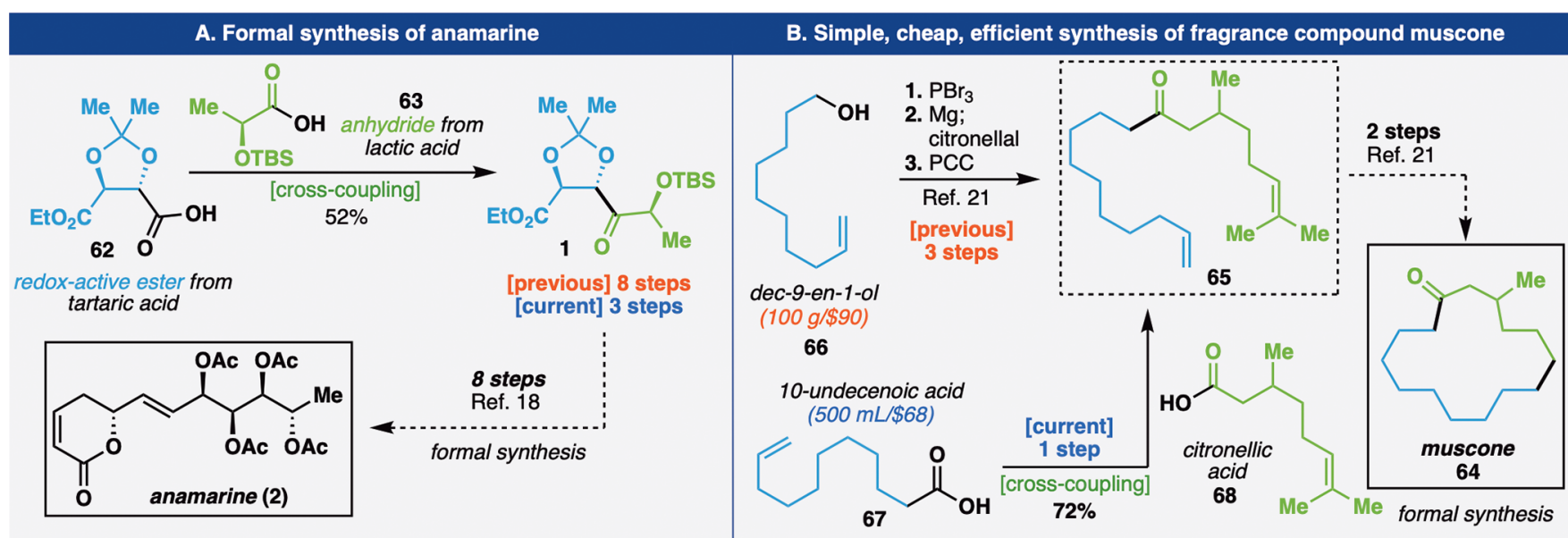

C. Pfizer med-chem intermediates (parallel library synthesis)

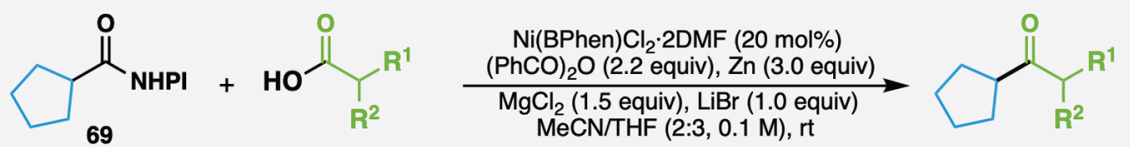

$0.1 \mathrm{mmol} \quad 2.0$ equiv $\quad>1.0 \mathrm{mg}$ is enough for biological assays

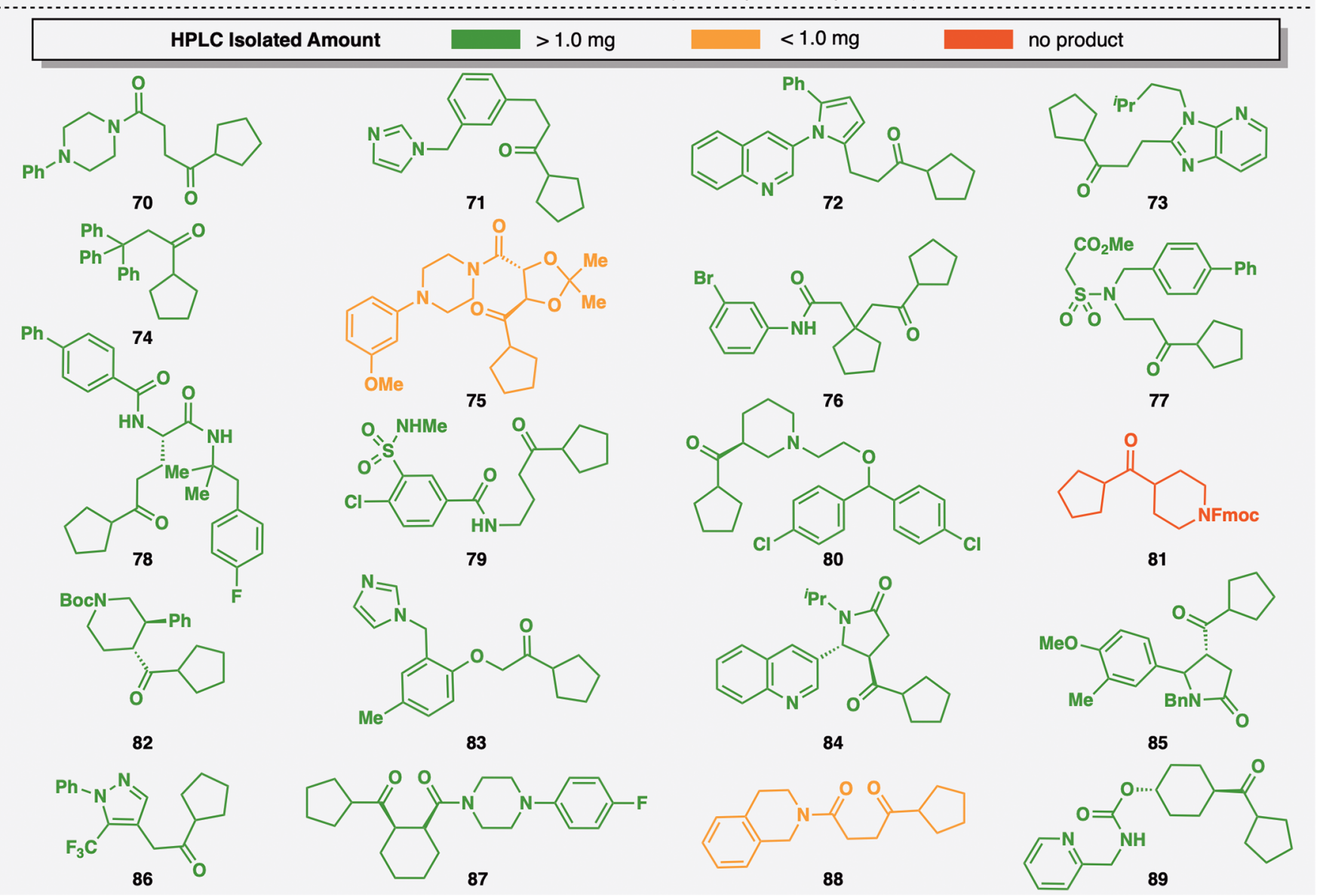

Figure 4. Applications of CCC to the formal synthesis of anamarine (A) and muscone (B), and parallel library synthesis (C). NHPI $=N$ hydroxyphthalimide.

$\left(\mathrm{R}={ }^{t} \mathrm{Bu}\right)$ failed due to competitive reduction of the sulfinimine (entry 2). Interestingly, unlike previous studies, where low yields of product were observed in the absence of $\mathrm{Ni}$ catalyst, the current reaction completely shuts down without it (with nearly quantitative imine recovery, entry 7 ).
With this new set of conditions in hand a range of $1^{\circ}, 2^{\circ}$, and $3^{\circ}$ carboxylic acids could be coupled with imine 92 via the corresponding RAE to rapidly provide a range of chiral benzylic amines in good yield and high dr (Table 3). Ethers (95 and 104), esters (98-100 and 103), Boc- and Tsprotected amines $(93,96,101,102,105$ and 106), pyridines 


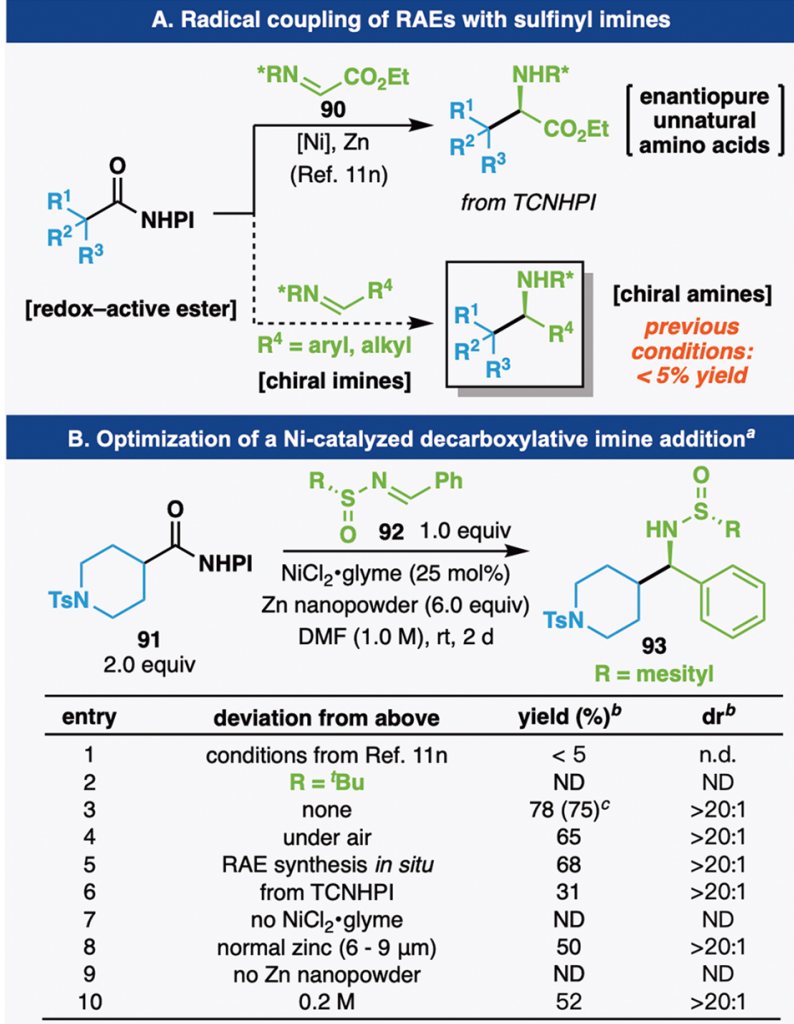

Figure 5. (A) Synthesis of amines from RAEs previously limited to amino acid synthesis and (B) an alternative protocol to access benzylic amines. ${ }^{a} 0.1 \mathrm{mmol}, \mathrm{Zn}$ nanopowder: $40-60 \mathrm{~nm}$ particle size. Aldrich catalog no. 578002. ${ }^{b}$ Yield and $\mathrm{dr}$ determined by ${ }^{1} \mathrm{H}$ NMR with 1,3,5-trimethoxybenzene as an internal standard. ${ }^{c}$ Isolated yield. See Supporting Information for details. NHPI $=N$-hydroxyphthalimide, TCNHPI $=N$-hydroxytetrachlorophthalimide, $\mathrm{ND}=$ not detected, n.d. $=$ not determined.

(103-105), and aryl halides (101 and 102) were all tolerated. Of the substrates screened, the most rapid and high yielding reactions involved bridgehead RAEs (97-100, and 103) presumably due to the increased stability and nucleophilicity of the putative radical intermediates. A notable limitation of this work is that alkyl sulfinyl imines are not viable coupling partners. The majority of products in Table 3 are novel (including their deprotected analogs). In the case of substrate 93, the deprotected racemic amine is expensive (from SigmaAldrich, ca. $\$ 1 / \mathrm{mg}$ ). ${ }^{25}$ The deprotected analog of 94 has been prepared in racemic form during the search for new kinase inhibitors by way of isonipecotic acid through a classical 3-step sequence (Weinreb amide, Grignard, reductive amination). ${ }^{26}$

\section{EXTENDING THE SCOPE OF NUCLEOPHILIC RAE CHEMISTRY: ALKYL NHK REACTIVITY}

The addition of standard $2 \mathrm{e}^{-}$-based nucleophiles to aldehydes is often beleaguered with competing enolization/polymerization problems (Figure 6A). The alkyl Nozaki-HiyamaKishi (NHK) reaction provides a viable solution to this issue but still requires an alkyl halide precursor. ${ }^{27}$ Shenvi and coworkers recently reported an impressive departure from this requirement by utilizing olefin-derived radicals in a $\mathrm{HAT} / \mathrm{Cr}$ system to deliver branched products from terminal olefins. ${ }^{28}$ At this juncture it is now self-evident that RAEs represent viable surrogates for alkyl halides in a myriad of different reactions
Table 3. Scope of the Radical Addition into Chiral Imines

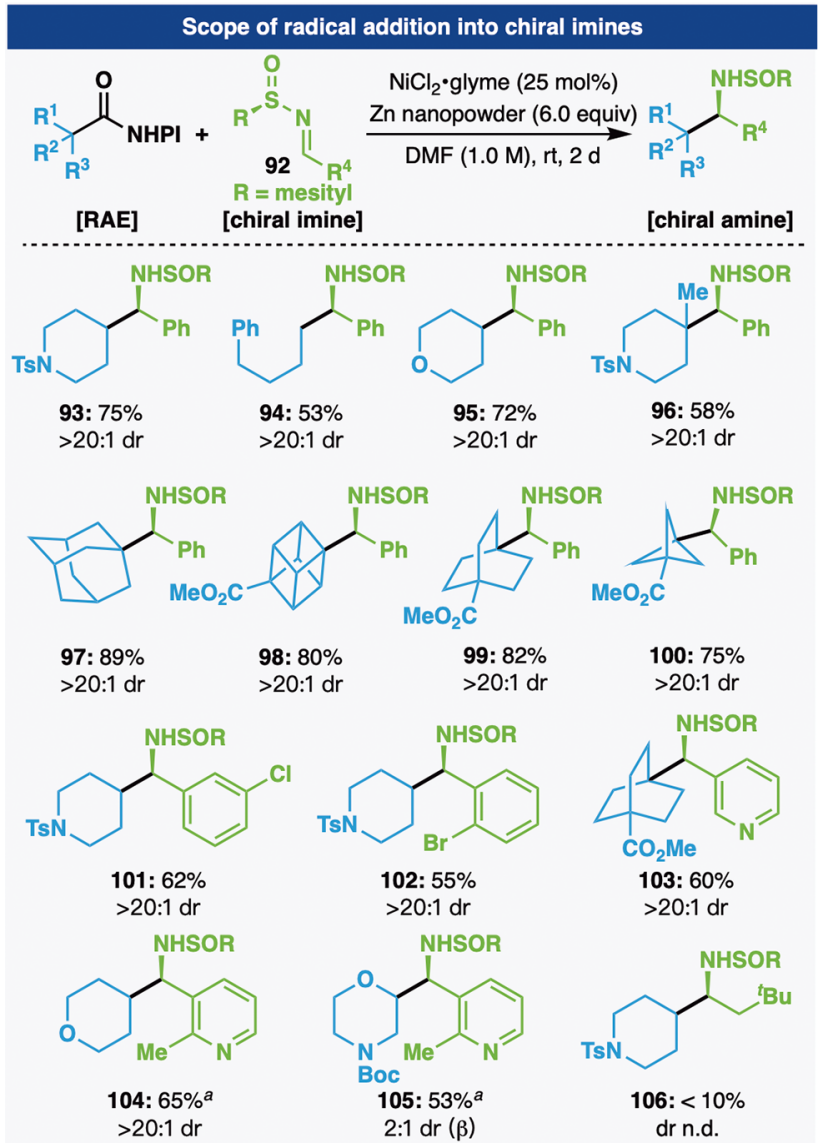

${ }^{a}$ See SI for reaction conditions. Standard reaction conditions: RAE (2.0 equiv), sulfinimine (1.0 equiv), $\mathrm{NiCl}_{2}$.glyme ( $25 \mathrm{~mol} \%$ ), $\mathrm{Zn}$ nanopowder (6.0 equiv), DMF $(1.0 \mathrm{M}), \mathrm{rt}, 2 \mathrm{~d}$. NHPI $=N$ hydroxyphthalimide.

under Ni-, Fe-, Co-, Cu-, Ru-, Pd-, and Ir-based catalysis. ${ }^{29}$ The use of alkyl halides in the classic NHK reaction is rare, and within the theme of utilizing RAEs to add to $\mathrm{C}=\mathrm{X}$ bonds, this seemed like a useful reaction to explore (Figure 6A). ${ }^{30}$ Access to such reactivity via RAEs versus olefins could provide a complementary solution to give linear rather than branched products.

The execution of a RAE-based alkyl NHK was straightforward and optimized conditions simply involved the addition of $\mathrm{RAE}$ to aldehyde in the presence of $\mathrm{CrCl}_{2}$ and $\mathrm{TMSCl}$ (Figure 6B). This is exemplified using model RAE 4 and aldehyde 107 to deliver TMS-protected alcohol 108 in $79 \%$ isolated yield. Although the RAE could be generated in situ to give a similar yield (entry 2), the reaction is sensitive to air (entry 3) and should be conducted using an $\mathrm{Ar}$ or $\mathrm{N}_{2}$ balloon. NHPI is the preferred RAE (entry 4) and $\mathrm{Cr}$ is clearly essential for the reaction (entry 5). The free alcohol could also be obtained in the absence of TMSCl, albeit in diminished yield (entry 6)..$^{31}$ Unlike the original alkyl NHK using alkyl halides, low-valent transition metal mediators such as $\mathrm{CoPc}$ or $\mathrm{Ni}$ have no effect on conversion (entries 7 and 8). ${ }^{30}$ However, excess $\mathrm{Cr}$ is still required (2.0 equiv leads to diminished yield, entry 9). Although reversing the stoichiometry of substrates had no effect, a lower yield was observed with 1 equiv of RAE (entries 10 and 11). The RAE-based alkyl NHK has admirable scope (Table 4) with regard to functional group compatibility 
A. Nozaki-Hiyama-Kishi (NHK) reaction with redox-active esters

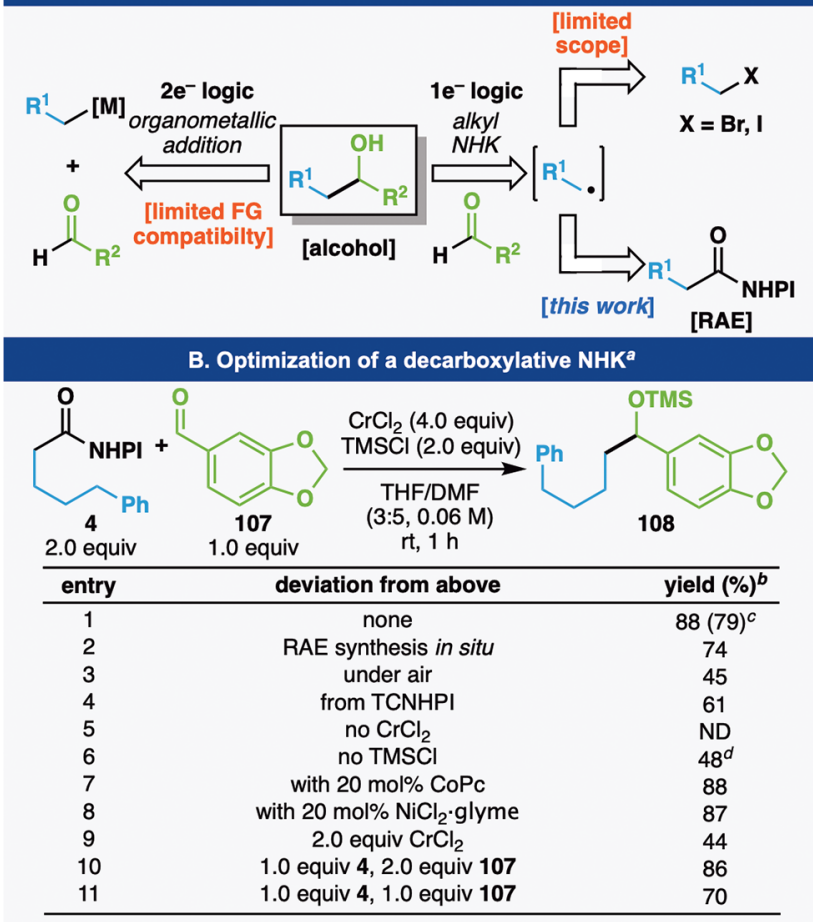

Figure 6. (A) Alcohol synthesis through conventional and radical means and (B) the development of an alkyl-NHK reaction employing RAEs. ${ }^{a} 0.1$ mmol. ${ }^{b}$ Yield determined by ${ }^{1} \mathrm{H}$ NMR with $1,3,5-$ trimethoxybenzene as an internal standard. ${ }^{c}$ Isolated yield. See Supporting Information for details. ${ }^{d}$ Isolated yield of the corresponding alcohol. NHPI $=N$-hydroxyphthalimide, TCNHPI $=$ $\mathrm{N}$-hydroxytetrachlorophthalimide, $\mathrm{ND}=$ not detected.

tolerating $N$-Boc-protected amines (109, 111, 112, and 115), halogens (110 and 117-119), and alkenes (113 and 122). Heterocyclic motifs such as azaindole and benzimidazole were also tolerated under the reaction conditions and compound 115 was afforded in $40 \%$ yield. Moreover, it is worth noting that selective addition at the 1,2 position was observed in the case of enone compound 123. However, only primary RAEs provide synthetically useful yields thus mirroring the historic limitations of alkyl-halide based NHK. In addition, pyridinecontaining building blocks did not afford synthetically useful yields (121).

\section{MECHANISTIC INQUIRY}

The synthetic utility of RAEs to function as nucleophilic (Grignard-like) reagents for the addition to $\mathrm{C}=\mathrm{X}$ bonds presents an exciting opportunity to interrogate this unique chemical reactivity. For this purpose, the CCC described above was chosen for in-depth study. ${ }^{32}$ Figure $7 \mathrm{~A}$ outlines the complete mechanistic picture of this transformation supported by kinetics, radical-clock studies, UV spectroscopy, isotopic labeling, and byproduct analysis. ${ }^{33}$

A catalytic cycle that is fully consistent with the data (Figure $7 \mathrm{~A}$, see high level summary) consists of initial oxidative addition by the electrophilically activated (anhydride or acyl chloride) carboxy group $\left(\mathrm{R}_{1}-\mathrm{CO}_{2} \mathrm{H}\right)$ to a ${ }^{t}$ Bubpy-ligated $\mathrm{Ni}(0)$ species I. Here, $\mathrm{MgCl}_{2}$ serves to facilitate the formation of a mixed anhydride species as verified in control studies outlined in inset $\mathrm{A}^{34}$ The critical oxidative addition step occurs rapidly to furnish acyl-bound $\mathrm{Ni}(\mathrm{II})$-carboxylate species II. Indeed,
Table 4. Scope of the Alkyl NHK Reactions with RAEs

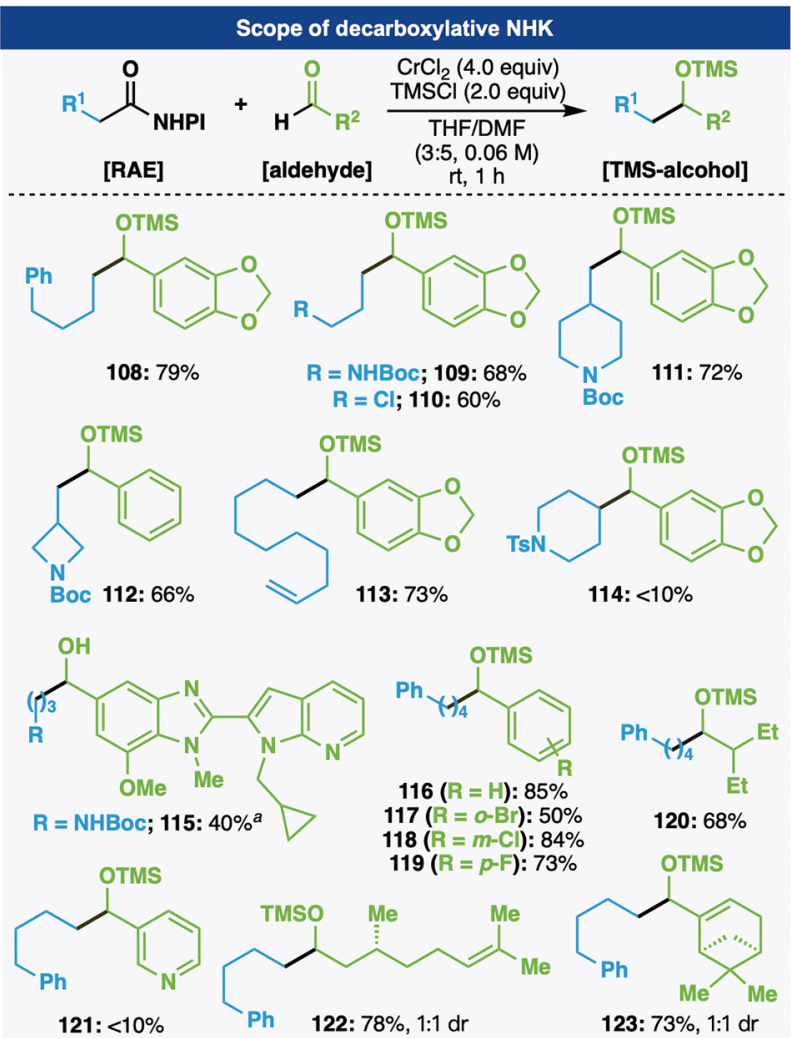

${ }^{a}$ See SI for reaction conditions. Standard reaction conditions: RAE (2.0 equiv), aldehydes (1.0 equiv), $\mathrm{CrCl}_{2}$ (4.0 equiv), TMSCl (2.0 equiv), THF/DMF (3:5, $0.06 \mathrm{M}), \mathrm{rt}, 1 \mathrm{~h}$. TMS = trimethylsilyl. NHPI $=N$-hydroxyphthalimide.

zero-order kinetics in acid/anhydride were measured, as evidenced in the kinetic orders, Figure 7. Selective insertion by $\mathrm{I}$ into the desired $\mathrm{C}-\mathrm{O}$ bond is likely dictated by electronics, wherein the electron-rich alkyl component better stabilizes electron-deficient $\mathrm{Ni}(\mathrm{II})$ species II. ${ }^{35}$ This step was confirmed through the discrete preparation of $\mathrm{Ni}(0)$ complex I (see insets B and C) and exposure to either a symmetrical anhydride or acyl chloride which both resulted in near instantaneous oxidative addition to complexes II and III, respectively. ${ }^{36}$ Subsequent ligand exchange (carboxylate for chloride) then occurs as supported by UV-vis spectroscopy wherein the addition of $\mathrm{MgCl}_{2}$ appears to convert II to III. ${ }^{37}$ It is also important to note that control studies with complex I and the RAE 127 lead to radical-based decomposition pathways rather than OA products (see SI). Competition experiments between RAE 127 and acyl chloride in the presence of complex I show complete consumption of the acyl chloride to the OA complex III (see SI). As aided by the persistent radical effect, ${ }^{38}$ complex III captures a radical derived from the $\mathrm{RAE}\left(\mathrm{R}^{2}\right.$-CONHPI) to deliver $\mathrm{Ni}(\mathrm{III})$ intermediate IV that undergoes rapid reductive elimination to provide the ketone product and $\mathrm{Ni}(\mathrm{I})$ complex $\mathbf{V}{ }^{39}$ The observation of small amounts of dimerized and decarboxylated byproducts from the RAE indicates that transient radical $\mathrm{R}^{2 \bullet}$ is captured by persistent metalloradical complex III (see "Byproduct analysis", Figure 7A and SI). Support for these two steps stems from the direct reaction of either complex II or III with RAE 127 (insets D and E). Presumably due to the 


\section{A. Proposed mechanism (boxed red letters indicate the presence of supporting evidence)}
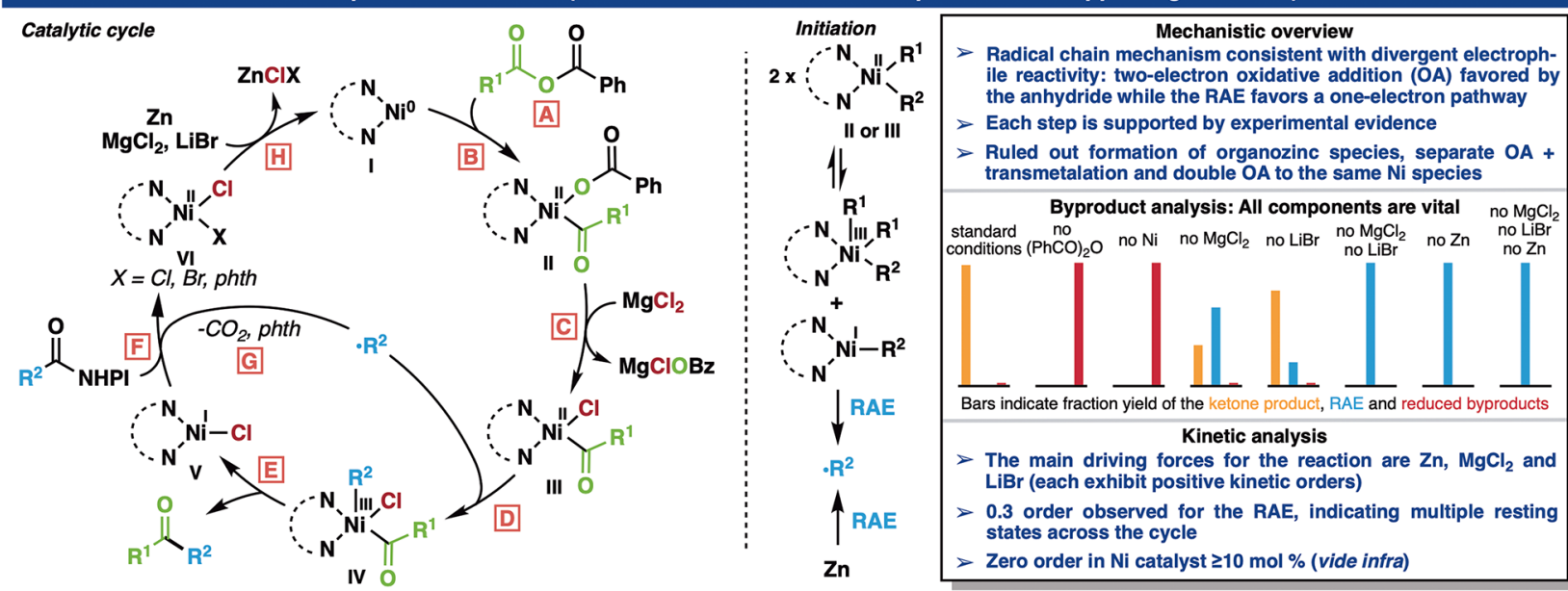

\section{B. Evidence supporting the mechanistic proposal}

A Formation of mixed and symmetrical anhydrides

$$
\underset{\mathrm{Ar}=(p-\mathrm{F}) \mathrm{C}_{6} \mathrm{H}_{4}}{\substack{\mathrm{MeCN} / \mathrm{THF}(2: 3,0.1 \mathrm{M}) \\ \mathrm{rt}, 30 \mathrm{~s}}}
$$

$>$ Anhydride formation facilitated by $\mathrm{MgCl}_{2}$

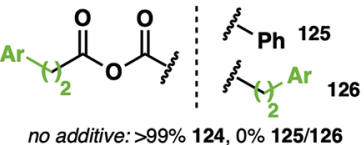
no additive: $>99 \% 124,0 \% 125 / 126$ $\mathrm{MgCl}_{2}: 0 \% 124,75 \% 125 / 126(83: 17)$ LiBr. $95 \% 124,5 \% 125 / 126$

> Isolated mixed anhydride is reactive under the standard conditions (see $\mathrm{SI}$ )

$B$ Oxidative addition $C$ Ligand exchange

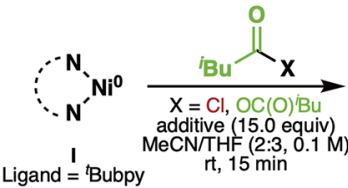
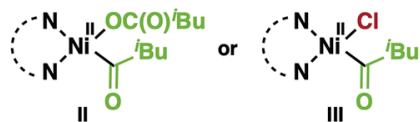

$>\mathrm{OA}$ to anhydride is rapid, consistent with previous reports Ligand exchange fast in the pres-
ence of $\mathrm{MgCl}_{2}$ and slow with LiBr

$>$ Oxidative addition by the RAE is avored to radical formation (see SI)

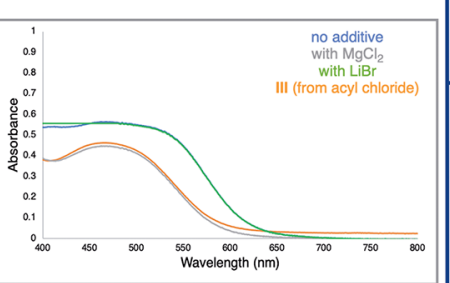

D Radical addition [E Reductive elimination

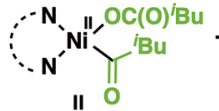

$$
\begin{aligned}
& 127(1.0 \text { equiv }) \\
& \mathrm{Ar}=(p-\mathrm{F}) \mathrm{C}_{6} \mathrm{H}_{4}
\end{aligned}
$$
$\mathrm{Zn}$ (3.0 equiv) $\mathrm{MeCN} / \mathrm{THF}$
$(2: 3,0.1 \mathrm{M})$ $\mathrm{rt}, 1 \mathrm{~h}$

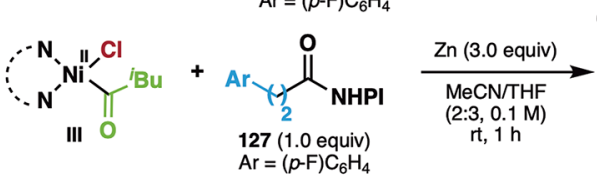

> Complex III from ligand exchange is more prevalent but less reactive > Reactivity without zinc supports initiation by disproportionation

\section{F Reduction of RAE by Ni complex $\mathbf{V}$ Mass balance of RAE + product at 4 min}

$>$ Ni catalyst protects the RAE from direct reduction by the $\mathrm{Zn}$ (positive order in $\mathrm{Ni}$ observed at lower concentrations)

$>$ Only decarboxylated and dimer byproducts were observed w/o Ni

Zero order in $\mathrm{Ni} \geq 10 \mathrm{~mol} \%$ indicative of off-cycle pathways
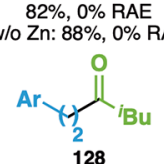

128

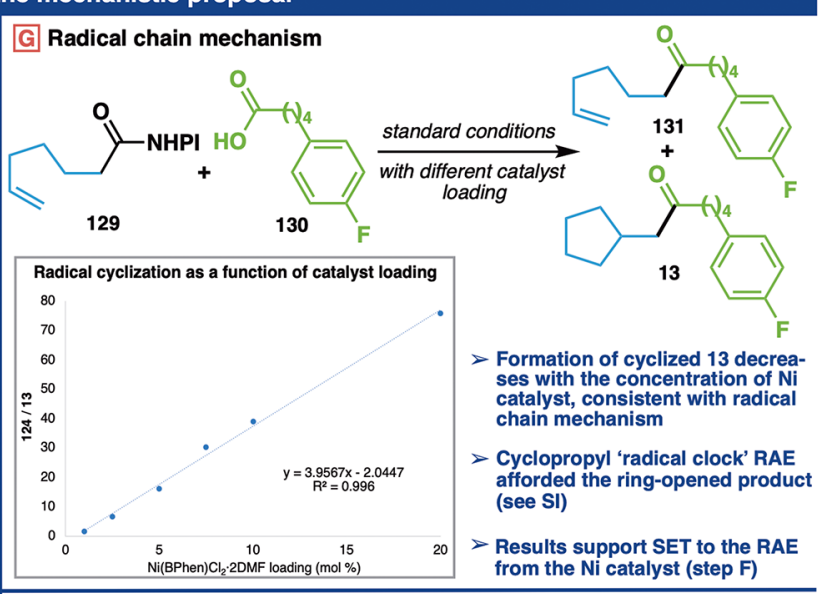

Heduction from $\mathrm{Ni}(\mathrm{II})$ to $\mathrm{Ni}(\mathrm{O})$
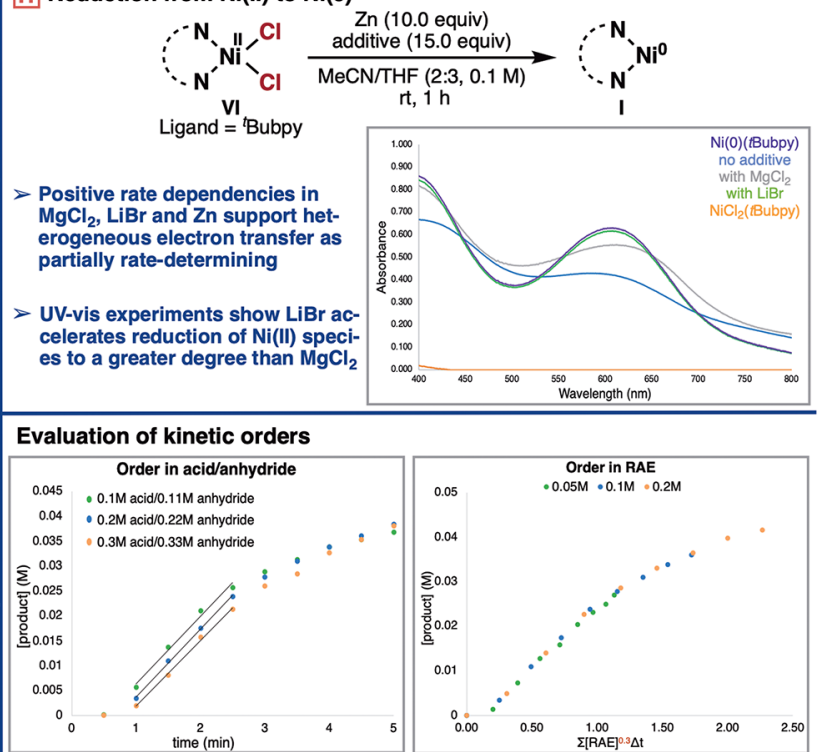

$>0$ order in acid/anhydride supports rapid formation of anhydride and $O A$

$>0.3$ order in RAE determined by variable time normalization analysis ${ }^{43}$

> No KIE observed for ${ }^{13} \mathrm{C}$-labeled RAE, consistent with fast decomposition (see SI)

Figure 7. CCC: complete mechanistic picture and supporting experiments. phth $=$ phthalimide.

differences in disproportionation rates for II and III, carboxylate complex II does not require the presence of a reductant whereas chloride complex III does (see "Initiation",
Figure $7 \mathrm{~A}) .^{40}$ Thus, either complex may exist in the reaction mixture and both of them can participate in the catalytic cycle. The $\mathrm{Ni}(\mathrm{I})$ complex $\mathbf{V}$ produced can then engage another 
molecule of RAE to perpetuate the cycle and generate $\mathrm{Ni}$ (II) species VI. ${ }^{41}$ Alternative pathways to RAE decomposition (to produce $\mathrm{R}^{2 \bullet}$ ) can be rationalized through disproportionation or via a $\mathrm{Ni} / \mathrm{Zn}$-mediated process (see "Initiation", Figure 7A). ${ }^{42}$ To deconvolute the role of $\mathrm{Ni}$ and $\mathrm{Zn}$ in the reductive cleavage of RAEs, the kinetics of this step were studied (inset F). Strikingly, if a RAE is exposed to standard reaction conditions in the absence of $\mathrm{Ni}$, it undergoes rapid decomposition to a mixture of dimerized and decarboxylated products without any ketone product (see "Byproduct analysis", Figure 7A and the SI for the kinetic profile). The chart in inset $\mathrm{F}$ illustrates the "buffering" effect of $\mathrm{Ni}$ to slow down $\mathrm{Zn}$-induced RAE consumption and increase product formation as the catalyst loading is increased. This creates a complex kinetic picture with slight positive orders in $\mathrm{Ni}$ at low catalyst loading and saturation kinetics observed at higher loadings $(>10 \%)$ possibly indicative of off-cycle pathways. These data, combined with that mentioned in insets D and E, support a Ni-based pathway for radical formation from the RAE. A positive kinetic order of 0.3 in the concentration of $\mathrm{RAE}$ is observed, suggesting it is involved in one of multiple rate-determining in this complex mechanistic pathway (see "Evaluation of kinetic orders", Figure 7B). ${ }^{43}$

The key evidence for a radical chain pathway came from analysis of the extent of cyclization upon exposure of RAE 129 and acid 130 to the standard reaction conditions (see inset G). ${ }^{44}$ The direct linear relationship between concentration of nickel catalyst and the ratio of $\mathbf{1 3 1}$ to $\mathbf{1 3}$ forges a mechanistic picture that is consistent with radical formation from complex $\mathrm{V}$, diffusion of $\mathrm{R}^{2 \bullet}$ out of the solvent cage (wherein cyclization is proposed to occur) before capture by complex III. ${ }^{7 \mathrm{~d}}$ The addition of more Ni catalyst to the reaction mixture shortens the lifetime of the radical in solution resulting in diminished cyclization. $\mathrm{Ni}(\mathrm{II})$-species VI is then reduced by $\mathrm{Zn}$ to afford complex I and complete the cycle. The observation of positive kinetic orders in $\mathrm{Zn}, \mathrm{MgCl}_{2}, \mathrm{LiBr}$ indicate this step may be partially rate determining and supports the crucial role that is experimentally observed for the additives (see SI for complete kinetic analysis). Indeed, a complete shutdown of reactivity occurs in the absence of $\mathrm{Zn}$ or both $\mathrm{MgCl}_{2}$ and $\mathrm{LiBr}$ (see "Byproduct analysis", Figure 7A and SI). To evaluate the effects of each additive on the reduction from complex VI to complex I, a solution of $\mathrm{NiCl}_{2}\left({ }^{t} \mathrm{Bubpy}\right)$ (inset $\mathrm{H}$, orange line) was stirred in the presence of $\mathrm{Zn}$ for an hour. The UV spectra (inset $\mathrm{H}$, blue line) clearly demonstrate formation of $\mathrm{Ni}(0)\left({ }^{t}\right.$ Bubpy) complex I (inset $\mathrm{H}$, purple line). However, addition of $\mathrm{MgCl}_{2}$ (inset $\mathrm{H}$, gray line) or $\mathrm{LiBr}$ (inset $\mathrm{H}$, green line) accelerated the reduction from $\mathrm{Ni}(\mathrm{II})$ to $\mathrm{Ni}(0), \mathrm{LiBr}$ to a greater extent. Thus, $\mathrm{MgCl}_{2}$ serves a triple role in facilitating anhydride formation (as a Lewis acid), ligand exchange (via salt metathesis), and $\mathrm{Ni}$ reduction.

To summarize, although the mechanistic picture outlined above is complex, each elementary step is supported, and the role of each essential additive is justified. The studies outlined above help in rationalizing the empirically generated user guide in Table 2 (vide supra) and should aid in the troubleshooting of difficult couplings or the large-scale implementation of CCC.

\section{CONCLUSION}

Barton's pioneering studies taught the community that there is much value in using carboxylic acids as precursors to a realm of new chemical space via $\mathrm{C}-\mathrm{C}$ breaking radical fragmentations rather than simple dehydrations (to make amides or esters). Barton esters, ${ }^{9 \mathrm{c}}$ Okada's NHPI esters, ${ }^{11 \mathrm{a}, \mathrm{b}}$ and other RAEs (e.g., TCNHPI, -OAt, or - $\mathrm{OBt}$ ) as well as redox-active pyridiniums $^{45}$ and sulfones ${ }^{46}$ all provide a useful way of breaking bonds in order to modularly install new ones in a versatile way. This study centered on the use of RAEs to access products that have heretofore resided within the scope of twoelectron retrosynthetic disconnections. In accessing common functional groups like ketones, alcohols, and amines, students are generally taught that polar bond analysis should lead to nucleophilic and electrophilic starting materials. Implementing radical retrosynthetic logic to the same targets results in the use of RAEs in an unusual way. Thus, these three functional groups can now be accessed commencing from readily available carboxylic acids via RAEs (which become the "nucleophilic" component) with mixed anhydrides, acyl halides, imines, or aldehydes (the canonical electrophilic component). Although certain limitations were encountered (Figure 8), these mild methods offer enhanced scope and

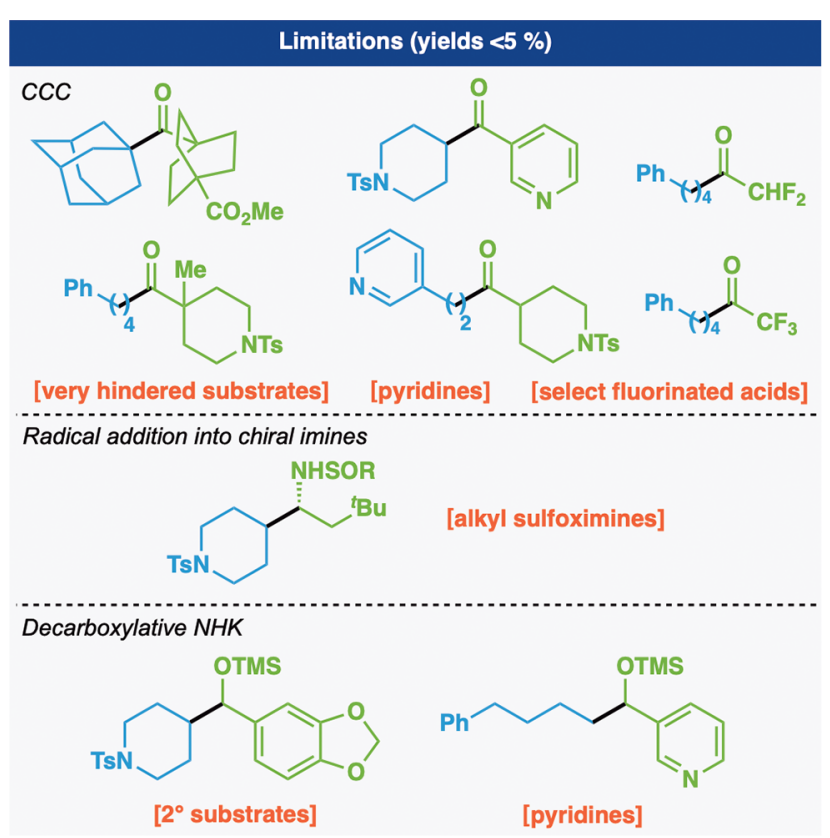

Figure 8. Limitations of the described methodologies.

orthogonal access to the same functionality previously accessed through two-electron chemistry and are amenable to parallel synthesis. In some cases, the enabled reactivity permits access to disconnections completely unavailable to the two-electron world (i.e., Figure 4).

\section{ASSOCIATED CONTENT}

\section{Supporting Information}

The Supporting Information is available free of charge on the ACS Publications website at DOI: 10.1021/jacs.9b02238.

Detailed experimental procedures and analytical data (PDF)

\section{AUTHOR INFORMATION}

\section{Corresponding Author}

*pbaran@scripps.edu

ORCID $\odot$

Natalia M. Padial: 0000-0001-6067-3360 
Cian Kingston: 0000-0002-2907-4260

Julien C. Vantourout: 0000-0002-0602-069X

Daniel C. Schmitt: 0000-0001-8786-9507

Phil S. Baran: 0000-0001-9193-9053

\section{Author Contributions}

Authors for this paper from independent organizations have all collaborated with the Baran lab independently on this work but are not collaborating with one another.

\section{Notes}

The authors declare no competing financial interest.

\section{ACKNOWLEDGMENTS}

Financial support for this work was provided by NIH (GM118176) and Pfizer. We gratefully thank the China Scholarship Council (CSC, S.N.), the Marie Skłodowska-Curie Global Fellowships (749359-EnanSET, N.M.P) within the European Union research and innovation framework programme (20142020), the Department of Defense (NDSEG fellowship to J.T.E.), Bristol-Myers Squibb (Graduate Fellowship to J.T.E.), Vividion (Graduate Fellowship to R.R.M.), and the Fulbright Scholar Program (P.K.M.). We would like to thank Enamine Ltd. for providing samples of several acids. We are grateful to Dr. Dee-Hua Huang and Dr. Laura Pasternack (Scripps Research) for assistance with NMR spectroscopy and Mr. Andrew Badwal (Pfizer) for high-throughput purification. We also thank Stephen Harwood (Scripps Research) for helpful advice and David Hill and Prof. Donna Blackmond (both Scripps Research) for assistance with the mechanistic studies.

\section{REFERENCES}

(1) (a) Grignard, V. Sur quelques nouvelles combinaisons organométalliques du magnésium et leurs applications à des synthèses d'alcools et d'hydrocarbures. C. R. Hebd. Séances. Acad. Sci. 1900, 130, 1322-1325. (b) Kagan, H. B. Victor Grignard and Paul Sabatier: Two Showcase Laureates of the Nobel Prize for Chemistry. Angew. Chem., Int. Ed. 2012, 51, 7376-7382.

(2) (a) Rogers, H. R.; Hill, C. L.; Fujiwara, Y.; Rogers, R. J.; Mitchell, H. L.; Whitesides, G. M. Mechanism of formation of Grignard reagents. Kinetics of reaction of alkyl halides in diethyl ether with magnesium. J. Am. Chem. Soc. 1980, 102, 217-226. (b) Walborsky, H. M. Mechanism of Grignard reagent formation. The surface nature of the reaction. Acc. Chem. Res. 1990, 23, 286293. (c) de Boer, H. J. R.; Akkerman, O. S.; Bickelhaupt, F. Carbanions as Intermediates in the Synthesis of Grignard Reagents. Angew. Chem., Int. Ed. Engl. 1988, 27, 687-689.

(3) Seyferth, D. The Grignard Reagents. Organometallics 2009, 28, 1598-1605. and references therein.

(4) Gaich, T.; Baran, P. S. Aiming for the Ideal Synthesis. J. Org. Chem. 2010, 75, 4657-4673.

(5) For selected examples of water tolerant organometallic reagents, see: (a) Fukuma, T.; Lock, S.; Miyoshi, N.; Wada, M. Water Accelerated Allylation of Aldehydes by Using Water Tolerant Grignard-Type Allylating Agents from Allylmagnesium Chloride and Various Metallic Salts. Chem. Lett. 2002, 31, 376-377. (b) Cicco, L.; Sblendorio, S.; Mansueto, R.; Perna, F. M.; Salomone, A.; Florio, S.; Capriati, V. Water opens the door to organolithiums and Grignard reagents: exploring and comparing the reactivity of highly polar organometallic compounds in unconventional reaction media towards the synthesis of tetrahydrofurans. Chem. Sci. 2016, 7, 1192-1199. (c) Zhou, F.; Li, C.-J. The Barbier-Grignard-type arylation of aldehydes using unactivated aryl iodides in water. Nat. Commun. 2014, 5, 4254.

(6) For reviews and selected examples, see: (a) Liu, R. Y.; Zhou, Y.; Yang, Y.; Buchwald, S. L. Enantioselective Allylation Using Allene, a Petroleum Cracking Byproduct. J. Am. Chem. Soc. 2019, 141, 2251-
2256. (b) Yang, Y.; Perry, I. B.; Buchwald, S. L. Copper-Catalyzed Enantioselective Addition of Styrene-Derived Nucleophiles to Imines Enabled by Ligand-Controlled Chemoselective Hydrocupration. J. Am. Chem. Soc. 2016, 138, 9787-9790. (c) Wang, Y.-M.; Bruno, N. C.; Placeres, A. L.; Zhu, S.; Buchwald, S. L. Enantioselective Synthesis of Carbo- and Heterocycles through a $\mathrm{CuH}$-Catalyzed Hydroalkylation Approach. J. Am. Chem. Soc. 2015, 137, 10524-10527. (d) Zhou, Y.; Bandar, J. S.; Buchwald, S. L. Enantioselective CuHCatalyzed Hydroacylation Employing Unsaturated Carboxylic Acids as Aldehyde Surrogates. J. Am. Chem. Soc. 2017, 139, 8126-8129. (e) Obora, Y.; Hatanaka, S.; Ishii, Y. Iridium-Catalyzed Coupling Reaction of Primary Alcohols with 1-Aryl-1-propynes Leading to Secondary Homoallylic Alcohols. Org. Lett. 2009, 11, 3510-3513. (f) Bower, J. F.; Kim, I. S.; Patman, R. L.; Krische, M. J. Catalytic Carbonyl Addition through Transfer Hydrogenation: A Departure from Preformed Organometallic Reagents. Angew. Chem., Int. Ed. 2009, 48, 34-46. (g) Kokubo, K.; Miura, M.; Nomura, M. RhodiumCatalyzed Reaction of Benzoic Anhydride with Styrene under Molecular Hydrogen. Organometallics 1995, 14, 4521-4524. (h) Kim, S. W.; Zhang, W.; Krische, M. J. Catalytic Enantioselective Carbonyl Allylation and Propargylation via Alcohol-Mediated Hydrogen Transfer: Merging the Chemistry of Grignard and Sabatier. Acc. Chem. Res. 2017, 50, 2371-2380. (i) Nguyen, K. D.; Park, B. Y.; Luong, T.; Sato, H.; Garza, V. J.; Krische, M. J. Metal-catalyzed reductive coupling of olefin-derived nucleophiles: Reinventing carbonyl addition. Science 2016, 354, aah5133. (j) Deutsch, C.; Krause, N.; Lipshutz, B. H. CuH-Catalyzed Reactions. Chem. Rev. 2008, 108, 2916-2927. (k) Mohr, J.; Oestreich, M. Balancing C=C Functionalization and $\mathrm{C}=\mathrm{O}$ Reduction in $\mathrm{Cu}-\mathrm{H}$ Catalysis. Angew. Chem., Int. Ed. 2016, 55, 12148-12149.

(7) (a) Crossley, S. W. M.; Obradors, C.; Martinez, R. M.; Shenvi, R. A. Mn-, Fe-, and Co-Catalyzed Radical Hydrofunctionalizations of Olefins. Chem. Rev. 2016, 116, 8912-9000. (b) Green, S. A.; Crossley, S. W. M.; Matos, J. L. M.; Vásquez-Céspedes, S.; Shevick, S. L.; Shenvi, R. A. The High Chemofidelity of Metal-Catalyzed Hydrogen Atom Transfer. Acc. Chem. Res. 2018, 51 (11), 26282640. (c) Lo, J. C.; Kim, D.; Pan, C.-M.; Edwards, J. T.; Yabe, Y.; Gui, J.; Qin, T.; Gutiérrez, S.; Giacoboni, J.; Smith, M. W.; Holland, P. L.; Baran, P. S. Fe-Catalyzed C-C Bond Construction from Olefins via Radicals. J. Am. Chem. Soc. 2017, 139, 2484-2503. (d) Shevick, S. L.; Obradors, C.; Shenvi, R. A. Mechanistic Interrogation of Co/Ni-Dual Catalyzed Hydroarylation. J. Am. Chem. Soc. 2018, 140, 1205612068.

(8) Gooßen, L. J.; Rodríguez, N.; Gooßen, K. Carboxylic Acids as Substrates in Homogeneous Catalysis. Angew. Chem., Int. Ed. 2008, 47, 3100-3120.

(9) (a) Kolbe, H. Zersetzung der Valeriansäure durch den elektrischen Strom. Ann. Chem. Pharm. 1848, 64, 339-341. For an application in total synthesis, see: (b) Corey, E. J.; Sauers, R. R. The Synthesis of Pentacyclosqualene $\left(8,8^{\prime}\right.$-Cycloönocerene) and the $\alpha$ and $\beta$-Onoceradienes. J. Am. Chem. Soc. 1959, 81, 1739-1743. (c) Barton, D. H. R.; Zard, S. Z. Invention of New Reactions Useful in the Chemistry of Natural Products. Pure Appl. Chem. 1986, 58, 675684

(10) (a) Pitre, S. P.; Weires, N. A.; Overman, L. E. Forging C(sp3)$\mathrm{C}(\mathrm{sp} 3)$ Bonds with Carbon-Centered Radicals in the Synthesis of Complex Molecules. J. Am. Chem. Soc. 2019, 141, 2800-2813. (b) Smith, J. M.; Harwood, S. J.; Baran, P. S. Radical Retrosynthesis. Acc. Chem. Res. 2018, 51, 1807-1817. (c) Yan, M.; Lo, J. C.; Edwards, J. T.; Baran, P. S. Radicals: Reactive Intermediates with Translational Potential. J. Am. Chem. Soc. 2016, 138, 12692-12714.

(11) For seminal studies on the use of RAEs, see: (a) Okada, K.; Okamoto, K.; Oda, M. A New and Practical Method of Decarboxylation: Photosensitized Decarboxylation of N-Acyloxyphthalimides via Electron-Transfer Mechanism. J. Am. Chem. Soc. 1988, 110, 8736-8738. (b) Okada, K.; Okamoto, K.; Morita, N.; Okubo, K.; Oda, M. Photosensitized Decarboxylative Michael Addition Through N-(Acyloxy)phthalimides via an Electron-Transfer Mechanism. J. Am. Chem. Soc. 1991, 113, 9401-9402. For recent 
investigations, see: (c) Cornella, J.; Edwards, J. T.; Qin, T.; Kawamura, S.; Wang, J.; Pan, C.-M.; Gianatassio, R.; Schmidt, M.; Eastgate, M. D.; Baran, P. S. Practical Ni-Catalyzed Aryl-Alkyl CrossCoupling of Secondary Redox-Active Esters. J. Am. Chem. Soc. 2016, 138, 2174-2177. (d) Qin, T.; Cornella, J.; Li, C.; Malins, L. R.; Edwards, J. T.; Kawamura, S.; Maxwell, B. D.; Eastgate, M. D.; Baran, P. S. A General Alkyl-Alkyl Cross-Coupling Enabled by Redox-Active Esters and Alkylzinc Reagents. Science 2016, 352, 801-805. (e) Wang, J.; Qin, T.; Chen, T.-G.; Wimmer, L.; Edwards, J. T.; Cornella, J.; Vokits, B.; Shaw, S. A.; Baran, P. S. Nickel-Catalyzed Cross-Coupling of Redox-Active Esters with Boronic Acids. Angew. Chem., Int. Ed. 2016, 55, 9676-9679. (f) Toriyama, F.; Cornella, J.; Wimmer, L.; Chen, T.-G.; Dixon, D. D.; Creech, G.; Baran, P. S. Redox-Active Esters in Fe-Catalyzed C-C Coupling. J. Am. Chem. Soc. 2016, 138, 11132-11135. (g) Qin, T.; Malins, L. R.; Edwards, J. T.; Merchant, R. R.; Novak, A. J. E.; Zhong, J. Z.; Mills, R. B.; Yan, M.; Yuan, C.; Eastgate, M. D.; Baran, P. S. Nickel-Catalyzed Barton Decarboxylation and Giese Reactions: A Practical Take on Classic Transforms. Angew. Chem., Int. Ed. 2017, 56, 260-265. (h) Sandfort, F.; O'Neill, M. J.; Cornella, J.; Wimmer, L.; Baran, P. S. Alkyl(Hetero)aryl Bond Formation via Decarboxylative Cross-Coupling: A Systematic Analysis. Angew. Chem., Int. Ed. 2017, 56, 3319-3323. (i) Edwards, J. T.; Merchant, R. R.; McClymont, K. S.; Knouse, K. W.; Qin, T.; Malins, L. R.; Vokits, B.; Shaw, S. A.; Bao, D.-H.; Wei, F.L.; Zhou, T.; Eastgate, M. D.; Baran, P. S. Decarboxylative Alkenylation. Nature 2017, 545, 213-218. (j) Smith, J. M.; Qin, T.; Merchant, R. R.; Edwards, J. T.; Malins, L. R.; Liu, Z.; Che, G.; Shen, Z.; Shaw, S. A.; Eastgate, M. D.; Baran, P. S. Decarboxylative Alkynylation. Angew. Chem., Int. Ed. 2017, 56, 11906-11910. (k) Wang, J.; Lundberg, H.; Asai, S.; Martin-Acosta, P.; Chen, J. C.; Brown, S.; Farrell, W.; Dushin, R.; O’Donnell, C. J.; Ratnayake, A. S.; Richardson, P.; Liu, Z.; Qin, T.; Blackmond, D. G.; Baran, P. S. Kinetically Guided Radical-Based Synthesis of $\mathrm{C}\left(\mathrm{sp}^{3}\right)-\mathrm{C}\left(\mathrm{sp}^{3}\right)$ Linkages on DNA. Proc. Natl. Acad. Sci. U. S. A. 2018, 115, E6404-E6410. (1) Chen, T.-G.; Barton, L. M.; Lin, Y.; Tsien, J.; Kossler, D.; Bastida, I.; Asai, S.; Bi, C.; Chen, J. S.; Shan, M.; Fang, H.; Fang, F. G.; Choi, H.; Hawkins, L.; Qin, T.; Baran, P. S. Building $\mathrm{C}\left(\mathrm{sp}^{3}\right)$-Rich Complexity by Combining Cycloaddition and C-C Cross-Coupling Reactions. Nature 2018, 560, 350-354. (m) Wang, J.; Shang, M.; Lundberg, H.; Feu, K. S.; Hecker, S. J.; Qin, T.; Blackmond, D. G.; Baran, P. S. Cu-Catalyzed Decarboxylative Borylation. ACS Catal. 2018, 8, 9537-9542. (n) Ni, S.; GarridoCastro, A.; Merchant, R.; deGruyter, J.; Schmitt, D. C.; Mousseau, J. J.; Gallego, G. M.; Yang, S.; Collins, M. R.; Qiao, J. X.; Yeung, K.-S.; Langley, D. R.; Poss, M. A.; Scola, P. M.; Qin, T.; Baran, P. S. A General Amino Acid Synthesis Enabled by Innate Radical CrossCoupling. Angew. Chem., Int. Ed. 2018, 57, 14560-14565. (o) Huihui, K. M. M.; Caputo, J. A.; Melchor, Z.; Olivares, A. M.; Spiewak, A. M.; Johnson, K. A.; DiBenedetto, T. A.; Kim, S.; Ackerman, L. K. G.; Weix, D. J. Decarboxylative Cross-Electrophile Coupling of NHydroxyphthalimide Esters with Aryl Iodides. J. Am. Chem. Soc. 2016, 138, 5016-5019. (p) Jamison, C. R.; Overman, L. E. Fragment Coupling with Tertiary Radicals Generated by Visible-Light Photocatalysis. Acc. Chem. Res. 2016, 49, 1578-1586. (q) Fawcett, A.; Pradeilles, J.; Wang, Y.; Mutsuga, T.; Myers, E. L.; Aggarwal, V. K. Photoinduced Decarboxylative Borylation of Carboxylic Acids. Science 2017, 357, 283-286. (r) Zhao, W.; Wurz, R. P.; Peters, J. C.; Fu, G. C. Photoinduced, Copper-Catalyzed Decarboxylative $\mathrm{C}-\mathrm{N}$ Coupling to Generate Protected Amines: An Alternative to the Curtius Rearrangement. J. Am. Chem. Soc. 2017, 139, 12153-12156. (s) Candish, L.; Teders, M.; Glorius, F. Transition-Metal-Free, Visible-Light-Enabled Decarboxylative Borylation of Aryl N-Hydroxyphthalimide Esters. J. Am. Chem. Soc. 2017, 139, 7440-7443. (t) Li, H.; Breen, C. P.; Seo, H.; Jamison, T. F.; Fang, Y.-Q.; Bio, M. M. NiCatalyzed Electrochemical Decarboxylative C-C Couplings in Batch and Continuous Flow. Org. Lett. 2018, 20, 1338-1341. (u) Mao, R.; Balon, J.; Hu, X. Decarboxylative $\mathrm{C}\left(\mathrm{sp}^{3}\right)-\mathrm{O}$ Cross-Coupling. Angew. Chem., Int. Ed. 2018, 57, 13624-13628. (v) Liu, X.-G.; Zhou, C.-J.; Lin, E.; Han, X.-L.; Zhang, S.-S.; Li, Q.; Wang, H. Decarboxylative
Negishi Coupling of Redox-Active Aliphatic Esters by Cobalt Catalysis. Angew. Chem., Int. Ed. 2018, 57, 13096-13100. (w) Kingston, C.; Wallace, M. A.; Allentoff, A. J.; deGruyter, J. N.; Chen, J. S.; Gong, S. X.; Bonacorsi, S.; Baran, P. S. Direct Carbon Isotope Exchange through Decarboxylative Carboxylation. J. Am. Chem. Soc. 2019, 141, 774-779. (x) Chen, T. G.; Zhang, H.; Mykhailiuk, P. K.; Merchant, R. R.; Smith, C. A.; Qin, T.; Baran, P. S. Quaternary Centers by Nickel-Catalyzed Cross-Coupling of Tertiary Carboxylic Acids and (Hetero)Aryl Zinc Reagents. Angew. Chem., Int. Ed. 2019, $58,2454-2458$.

(12) Habeeb, J. J.; Tuck, D. G. Electrochemical synthesis of unsymmetric ketones and some related coupling reactions. J. Chem. Soc., Chem. Commun. 1976, 17, 696-697.

(13) Gisselbrecht, J. P.; Lund, H. Electrochemical Reduction of Trichloromethylbenzene II Reduction in the Presence of Electrophiles. Acta Chem. Scand. 1985, 39, 823-827.

(14) (a) Marzouk, H.; Rollin, Y.; Folest, J. C.; Nédélec, J. Y.; Périchon, J. Electrochemical synthesis of ketones from acid chlorides and alkyl and aryl halides catalysed by nickel complexes. J. Organomet. Chem. 1989, 369, C47-C50. (b) Amatore, C.; Jutand, A.; Périchon, J.; Rollin, Y. Mechanism of the Nickel-Catalyzed Electrosynthesis of Ketones by Heterocoupling of Acyl and Benzyl Halides. Monatsh. Chem. 2000, 131, 1293-1304.

(15) Onaka, M.; Matsuoka, Y.; Mukaiyama, T. A convenient method for the direct preparation of ketones from 2-(6-(2-methoxyethyl)pyridyl) carboxylates and alkyl iodides by use of zinc dust and a catalytic amount of nickel dichloride. Chem. Lett. 1981, 10, 531-534.

(16) (a) Yin, H.; Zhao, C.; You, H.; Lin, K.; Gong, H. Mild ketone formation via Ni-catalyzed reductive coupling of unactivated alkyl halides with acid anhydrides. Chem. Commun. 2012, 48, 7034-7036. (b) Wotal, A. C.; Weix, D. J. Synthesis of Functionalized Dialkyl Ketones from Carboxylic Acid Derivatives and Alkyl Halides. Org. Lett. 2012, 14, 1476-1479. (c) Cherney, A. H.; Kadunce, N. T.; Reisman, S. E. Catalytic Asymmetric Reductive Acyl Cross-Coupling: Synthesis of Enantioenriched Acyclic $\alpha, \alpha$-Disubstituted Ketones. J. Am. Chem. Soc. 2013, 135, 7442-7445. (d) Jia, X.; Zhang, X.; Qian, Q.; Gong, H. Alkyl-aryl ketone synthesis via nickel-catalyzed reductive coupling of alkyl halides with aryl acids and anhydrides. Chem. Commun. 2015, 51, 10302-10305. For reviews, see: (e) Moragas, T.; Correa, A.; Martin, R. Metal-Catalyzed Reductive Coupling Reactions of Organic Halides with Carbonyl-Type Compounds. Chem. - Eur. J. 2014, 20, 8242-8258. (f) Everson, D. A.; Weix, D. J. Cross-Electrophile Coupling: Principles of Reactivity and Selectivity. J. Org. Chem. 2014, 79, 4793-4798.

(17) (a) Zheng, M.; Xue, W.; Xue, T.; Gong, H. Ester Formation via Nickel-Catalyzed Reductive Coupling of Alkyl Halides with Chloroformates. Org. Lett. 2016, 18, 6152-6155. (b) Huihui, K. M. M.; Caputo, J. A.; Melchor, Z.; Olivares, A. M.; Spiewak, A. M.; Johnson, K. A.; DiBenedetto, T. A.; Kim, S.; Ackerman, L. K. G.; Weix, D. J. Decarboxylative Cross-Electrophile Coupling of $\mathrm{N}$ Hydroxyphthalimide Esters with Aryl Iodides. J. Am. Chem. Soc. 2016, 138, 5016-5019. (c) Koyanagi, T.; Herath, A.; Chong, A.; Ratnikov, M.; Valiere, A.; Chang, J.; Molteni, V.; Loren, J. One-Pot Electrochemical Nickel-Catalyzed Decarboxylative $\mathrm{Sp}^{2}-\mathrm{Sp}^{3}$ CrossCoupling. Org. Lett. 2019, 21, 816-820. For a recent report on the synthesis of aryl alkyl ketones from aldehydes and RAEs, see: (d) Ishii, T.; Kakeno, Y.; Nagao, K.; Ohmiya, H. N-Heterocyclic Carbene-Catalyzed Decarboxylative Alkylation of Aldehydes. J. Am. Chem. Soc. 2019, 141, 3854-3858.

(18) Gao, D.; O’Doherty, G. A. De Novo Asymmetric Synthesis of Anamarine and Its Analogues. J. Org. Chem. 2005, 70, 9932-9939.

(19) Prescher, J. A.; Bertozzi, C. R. Chemistry in living systems. Nat. Chem. Biol. 2005, 1, 13-21.

(20) (a) Reekie, T. A.; Williams, C. M.; Rendina, L. M.; Kassiou, M. Cubanes in Medicinal Chemistry. J. Med. Chem. 2019, 62, 10781095. (b) Mykhailiuk, P. K. Saturated bioisosteres of benzene: where to go next? Org. Biomol. Chem. 2019, 17, 2839-2849. (c) Locke, G. M.; Bernhard, S. S. R.; Senge, M. O. Nonconjugated Hydrocarbons as 
Rigid-Linear Motifs: Isosteres for Material Sciences and Bioorganic and Medicinal Chemistry. Chem. - Eur. J. 2019, 25, 4590-4647.

(21) (a) Narula, A. P. S.; Arruda, E. M.; Amorelli, B.; Schiet, F. T. 3methyl-6-cyclohexadecen-1-one and its use in perfume compositions. US Patent US20130052151A1, 2013. (b) Morin, E.; Sosoe, J.; Raymond, M.; Amorelli, B.; Boden, R. M.; Collins, S. K. Synthesis of a Renewable Macrocyclic Musk: Evaluation of Batch, Microwave, and Continuous Flow Strategies. Org. Process Res. Dev. 2019, 23, 283-287.

(22) Lipinski, C. A.; Lombardo, F.; Dominy, B. W.; Feeney, P. J. Experimental and Computational Approaches to Estimate Solubility and Permeability in Drug Discovery and Development Settings. Adv. Drug Delivery Rev. 1997, 23, 3-25.

(23) Murray, C. W.; Rees, D. C. The rise of fragment-based drug discovery. Nat. Chem. 2009, 1, 187-192.

(24) (a) Friestad, G. K.; Qin, J. Highly Stereoselective Intermolecular Radical Addition to Aldehyde Hydrazones from a Chiral 3-Amino-2-oxazolidinone. J. Am. Chem. Soc. 2000, 122, 83298330. (b) Friestad, G. K.; Qin, J. Intermolecular Alkyl Radical Addition to Chiral N-Acylhydrazones Mediated by Manganese Carbonyl. J. Am. Chem. Soc. 2001, 123, 9922-9923. (c) Friestad, G. K.; Shen, Y.; Ruggles, E. L. Enantioselective Radical Addition to NAcylhydrazones Mediated by Chiral Lewis Acids. Angew. Chem., Int. Ed. 2003, 42, 5061-5063. (d) Friestad, G. K.; Ji, A.; Baltrusaitis, J.; Korapala, C. S.; Qin, J. Scope of Stereoselective Mn-Mediated Radical Addition to Chiral Hydrazones and Application in a Formal Synthesis of Quinine. J. Org. Chem. 2012, 77, 3159-3180. (e) Friestad, G. K.; Banerjee, K.; Marié, J.-C.; Mali, U.; Yao, L. Stereoselective Access to Tubuphenylalanine and Tubuvaline: Improved Mn-Mediated Radical Additions and Assembly of A Tubulysin Tetrapeptide Analog. J. Antibiot. 2016, 69, 294-298.

(25) Catalog no. ENA371463686.

(26) Caldwell, J. J.; Davies, T. G.; Donald, A.; McHardy, T.; Rowlands, M. G.; Aherne, G. W.; Hunter, L. K.; Taylor, K.; Ruddle, R.; Raynaud, F. I.; Verdonk, M.; Workman, P.; Garrett, M. D.; Collins, I. Identification of 4-(4-Aminopiperidin-1-yl)-7H-pyrrolo[2,3-d]pyrimidines as Selective Inhibitors of Protein Kinase B through Fragment Elaboration. J. Med. Chem. 2008, 51, 2147-2157.

(27) Fürstner, A. Carbon-Carbon Bond Formations Involving Organochromium (III) Reagents. Chem. Rev. 1999, 99, 991-1046.

(28) Matos, J. L. M.; Vásquez-Céspedes, S.; Gu, J.; Oguma, T.; Shenvi, R. A. Branch-Selective Addition of Unactivated Olefins into Imines and Aldehydes. J. Am. Chem. Soc. 2018, 140, 16976-16981.

(29) Murarka, S. N-(Acyloxy)phthalimides as Redox-Active Esters in Cross-Coupling Reactions. Adv. Synth. Catal. 2018, 360, 1735-1753.

(30) (a) Takai, K. Addition of Organochromium Reagents to Carbonyl Compounds. Organic Reactions 2004, 64, 253-626. (b) Takai, K.; Kimura, K.; Kuroda, T.; Hiyama, T.; Nozaki, H. Selective Grignard-type Carbonyl Addition of Alkenyl Halides Mediated by chromium(II) Chloride. Tetrahedron Lett. 1983, 24, 5281-5284. (c) Takai, K.; Tagashira, M.; Kuroda, T.; Oshima, K.; Utimoto, K.; Nozaki, H. Reactions of Alkenylchromium Reagents Prepared from Alkenyl Trifluoromethanesulfonates (Triflates) with chromium(II) Chloride under Nickel Catalysis. J. Am. Chem. Soc. 1986, 108, 6048-6050.

(31) Fürstner, A.; Shi, N. A Multicomponent Redox System Accounts for the First Nozaki-Hiyama-Kishi Reactions Catalytic in Chromium. J. Am. Chem. Soc. 1996, 118, 2533-2534.

(32) For general reviews on the mechanism of Ni-catalyzed crosscoupling reactions, see: (a) Hu, X. Nickel-catalyzed cross coupling of non-activated alkyl halides: a mechanistic perspective. Chem. Sci. 2011, 2, 1867-1886. (b) Tasker, S. Z.; Standley, E. A.; Jamison, T. F. Recent advances in homogeneous nickel catalysis. Nature 2014, 509, 299-309. (c) Lucas, E. L.; Jarvo, E. R. Keeping Track of the Electrons. Acc. Chem. Res. 2018, 51, 567-572.

(33) Alternative pathways consisting of in situ organometallic formation, oxidative addition of the two substrates to two separate $\mathrm{Ni}$ species, followed by transmetalation or consecutive double oxidative addition to the same $\mathrm{Ni}$ species were ruled out through the mechanistic experiments in Figure 7 and further studies fully detailed in the SI. For information on these mechanistic pathways, see: (a) Biswas, S.; Weix, D. J. Mechanism and Selectivity in NickelCatalyzed Cross-Electrophile Coupling of Aryl Halides with Alkyl Halides. J. Am. Chem. Soc. 2013, 135, 16192-16197. (b) Everson, D. A.; Jones, B. A.; Weix, D. J. Replacing Conventional Carbon Nucleophiles with Electrophiles: Nickel-Catalyzed Reductive Alkylation of Aryl Bromides and Chlorides. J. Am. Chem. Soc. 2012, 134, 6146-6159. For previous DFT studies on the preference for radical chain or consecutive double oxidative addition pathways in $\mathrm{Ni}$ catalyzed cross-couplings, see: (c) Ren, Q.; Jiang, F.; Gong, H. DFT study of the single electron transfer mechanisms in Ni-Catalyzed reductive cross-coupling of aryl bromide and alkyl bromide. J. Organomet. Chem. 2014, 770, 130-135. (d) Wang, X.; Ma, G.; Peng, Y.; Pitsch, C. E.; Moll, B. J.; Ly, T. D.; Wang, X.; Gong, H. NiCatalyzed Reductive Coupling of Electron-Rich Aryl Iodides with Tertiary Alkyl Halides. J. Am. Chem. Soc. 2018, 140, 14490-14497.

(34) A mixed anhydride was synthesized, isolated, and found to be reactive under the standard conditions; see the SI for full details.

(35) (a) Xu, S.; Jiang, J.; Ding, L.; Fu, Y.; Gu, Z. Palladium/ Norbornene-Catalyzed ortho Aliphatic Acylation with Mixed Anhydride: Selectivity and Reactivity. Org. Lett. 2018, 20, 325-328. Oxidative addition of $\mathrm{Ni}$ (bpy) species to cyclic anhydrides has been shown to be fast and reversible, see: (b) Johnson, J. B.; Bercot, E. A.; Rowley, J. M.; Coates, G. W.; Rovis, T. Ligand-Dependent Catalytic Cycle and Role of Styrene in Nickel-Catalyzed Anhydride CrossCoupling: Evidence for Turnover-Limiting Reductive Elimination. J. Am. Chem. Soc. 2007, 129, 2718-2725.

(36) For UV studies on the oxidative addition of $\mathrm{Ni}(0)$ species to cyclic anhydrides, see: Stache, E. E.; Rovis, T.; Doyle, A. G. Dual Nickel- and Photoredox-Catalyzed Enantioselective Desymmetrization of Cyclic meso-Anhydrides. Angew. Chem., Int. Ed. 2017, 56, 3679-3683.

(37) The results are consistent with Gong's report, see: (a) Zhao, C.; Jia, X.; Wang, X.; Gong, H. Ni-Catalyzed Reductive Coupling of Alkyl Acids with Unactivated Tertiary Alkyl and Glycosyl Halides. J. Am. Chem. Soc. 2014, 136, 17645-17651. $\mathrm{MgCl}_{2}$ may also influence the dielectric constant of the solvent: (b) McCann, L. C.; Organ, M. G. On the Remarkably Different Role of Salt in the Cross-Coupling of Arylzincs From That Seen with Alkylzincs. Angew. Chem., Int. Ed. 2014, 53, 4386-4389. Li salts have been shown to clean the surface of $\mathrm{Zn}$ by removal of organometallic species: (c) Feng, C.; Cunningham, D. W.; Easter, Q. T.; Blum, S. A. Role of $\mathrm{LiCl}$ in Generating Soluble Organozinc Reagents. J. Am. Chem. Soc. 2016, $138,11156-11159$.

(38) For reviews, see: (a) Studer, A. The Persistent Radical Effect in Organic Synthesis. Chem. - Eur. J. 2001, 7, 1159-1164. (b) Fischer, H. The Persistent Radical Effect: A Principle for Selective Radical Reactions and Living Radical Polymerizations. Chem. Rev. 2001, 101, $3581-3610$.

(39) For a study on the reactivity of a $\mathrm{Ni}(\mathrm{III})$ species, see: Zheng, B.; Tang, F.; Luo, J.; Schultz, J. W.; Rath, N. P.; Mirica, L. M. Organometallic Nickel(III) Complexes Relevant to Cross-Coupling and Carbon-Heteroatom Bond Formation Reactions. J. Am. Chem. Soc. 2014, 136, 6499-6504.

(40) In contrast to the results with complexes II and III, no product formation is observed using $\mathrm{Ni}(\mathrm{BPhen}) \mathrm{Cl}_{2} \cdot 2 \mathrm{DMF}$ without zinc under the standard reaction conditions (see "Byproduct analysis", Figure $7 \mathrm{~A})$, indicating this species does not disproportionate and initiate radical formation.

(41) For a study on the reactivity of a $\mathrm{Ni}(\mathrm{I})$ species, see: Jones, G. D.; Martin, J. L.; McFarland, C.; Allen, O. R.; Hall, R. E.; Haley, A. D.; Brandon, R. J.; Konovalova, T.; Desrochers, P. J.; Pulay, P.; Vicic, D. A. Ligand Redox Effects in the Synthesis, Electronic Structure, and Reactivity of an Alkyl-Alkyl Cross-Coupling Catalyst. J. Am. Chem. Soc. 2006, 128, 13175-13183.

(42) Such pathways to initiation have also been proposed in crosselectrophile coupling with alkyl halides; see ref 33a.

(43) The precise kinetic order was determined by variable time normalization analysis (VTNA), see: (a) Nielsen, C. D. T.; Burés, J. 
Visual kinetic analysis. Chem. Sci. 2019, 10, 348-353 The results contrast our previous investigations wherein zero-order in RAE was observed; see ref $11 \mathrm{k}$ and $11 \mathrm{~m}$.

(44) For selected recent examples of radical chain mechanisms in $\mathrm{Ni}$ catalysis, see: (a) Ref 33. (b) Ref 37a. (c) Breitenfeld, J.; Ruiz, J.; Wodrich, M. D.; Hu, X. Bimetallic Oxidative Addition Involving Radical Intermediates in Nickel-Catalyzed Alkyl-Alkyl Kumada Coupling Reactions. J. Am. Chem. Soc. 2013, 135, 12004-12012. (d) Schley, N. D.; Fu, G. C. Nickel-Catalyzed Negishi Arylations of Propargylic Bromides: A Mechanistic Investigation. J. Am. Chem. Soc. 2014, 136, 16588-16593. For general discussion, see: (e) Lucas, E. L.; Jarvo, E. R. Stereospecific and stereoconvergent cross-couplings between alkyl electrophiles. Nat. Rev. Chem. 2017, 1, 0065. (f) Weix, D. J. Methods and Mechanisms for Cross-Electrophile Coupling of $\mathrm{Csp}^{2}$ Halides with Alkyl Electrophiles. Acc. Chem. Res. 2015, 48, $1767-1775$

(45) (a) Basch, C. H.; Liao, J.; Xu, J.; Piane, J. J.; Watson, M. P. Harnessing Alkyl Amines as Electrophiles for Nickel-Catalyzed Cross Couplings via C-N Bond Activation. J. Am. Chem. Soc. 2017, 139, 5313-5316. (b) Plunkett, S.; Basch, C. H.; Santana, S. O.; Watson, M. P. Harnessing Alkyl Pyridinium Salts as Electrophiles in Deaminative Alkyl-Alkyl Cross-Couplings. J. Am. Chem. Soc. 2019, 141, 2257-2262.

(46) Merchant, R. R.; Edwards, J. T.; Qin, T.; Kruszyk, M. M.; Bi, C.; Che, G.; Bao, D.-H.; Qiao, W.; Sun, L.; Collins, M. R.; Fadeyi, O. O.; Gallego, G. M.; Mousseau, J. J.; Nuhant, P.; Baran, P. S. Modular radical cross-coupling with sulfones enables access to $\mathrm{sp}^{3}$-rich (fluoro)alkylated scaffolds. Science 2018, 360, 75-80.

\section{NOTE ADDED AFTER ASAP PUBLICATION}

Due to a production error, Table 4 was misrepresented in the version published on April 16, 2019 and has been corrected. Associated compound numbers in the text have been adjusted accordingly; this reposted on April 24, 2019. 